\title{
How Accurate Are Commercial Real Estate Appraisals? Evidence from 25 Years of NCREIF Sales Data
}

\author{
Susanne E. Cannon \\ Department of Real Estate \\ DePaul University \\ Chicago, IL 60604 USA \\ scannon@depaul.edu \\ $312-362-5706$ \\ Rebel A. Cole \\ Departments of Real Estate and Finance \\ DePaul University \\ Chicago, IL 60604 USA \\ rcole@depaul.edu \\ 312-362-6887
}

\begin{abstract}
In this study, we provide new evidence on the performance measurement and reporting of commercial real estate returns. We do so by examining the accuracy of commercial real-estate appraisals that occurred prior to the sale of properties from the NCREIF National Property Index ("NPI") during 1984 - 2010, a period which spans two up-and-down cycles of the market. We find that, on average, appraisals are more than $10 \%$ above, or below, subsequent sales prices that take place two quarters following the appraisal. Even in a portfolio context, allowing for offsetting positive and negative differences, appraisals are off by an average of $5 \%$ of value. We also provide new evidence regarding how, and by how much, appraised values lag behind sales prices. This new evidence provides guidance to investors, regulators and others about how to interpret real-estate indices like the NPI that are based upon appraised values, in both a rising and falling market.
\end{abstract}

DRAFT: February 6th, 2011

Do not quote without permission of authors.

We are grateful to the Real Estate Research Institute for financial support and to the National Council of Real Estate Investment Fiduciaries ("NCREIF") for supplying data on NPI properties. We thank Jeff Fisher, Martha Peyton, Ed Pierzsak, Doug Poutasse, and Elaine Worzala for helpful comments. 


\section{How Accurate Are Commercial Real Estate Appraisals? Evidence from 25 Years of NCREIF Sales Data}

\section{Introduction}

As the commercial real estate industry emerges from the worst downturn since the crash of the early 1990s, the issues of performance measurement and reporting have once again taken center stage. Sales prices plummeted during 2008 and 2009, but what happened to the appraised values upon which investors rely for quarterly valuations? Did they accurately reflect the declines in value so readily observable in sales prices, or did they lag these declines, resulting in overvaluation within their portfolio and the NCREIF index?

In this study, we provide important new evidence on this issue by examining the accuracy of commercial real estate appraisals that occurred prior to the sale of properties from the portfolios of commingled real estate funds that contribute data to the NCREIF property database. By examining sales over the past 25 years covered by NCREIF, from 1984 - 2010, we are able to determine whether or not appraised values lag sales prices, and if so, by how much.

We provide new evidence regarding how much confidence an investor can place in the appraisal of a single property, as well as how much confidence an investor can place in the appraisals of a portfolio of properties. We also provide evidence on how well appraisals track the cycle of the commercial real estate market. This new evidence provides guidance to investors about how to interpret appraised values, as well as property indices based upon those values, in both a rising and falling market.

Our study is important because investors, regulators, and others rely upon appraised values to assess returns on the $\$ 4$ trillion U.S. commercial real estate market since properties 
transact infrequently. The most widely used index of commercial real estate returns-NCREIF National Property Index (“NPI”)—is based upon quarterly appraised values. ${ }^{1}$

In addition, more than $\$ 200$ billion in pension-fund investments are held in private commingled real-estate funds ("CREFs") as of the end of 2009; many of these CREFs are socalled "open" funds, where investors can buy in and sell out based upon the aggregate appraised values of fund properties. If appraised values differ materially from market values, then informed investors can expropriate wealth from uninformed investors by moving in and out of these funds based upon their superior information. The larger the differential in appraised values and market values, the worse this problem becomes.

Finally, to the extent that firms managing the investments of pension funds benchmark their performance against the index, and use that benchmark to determine fees paid, the overstatement or understatement of appraised values can lead to distortions.

\section{Literature}

There are several studies that have examined the reliability of commercial appraisals, but most are now quite dated and rely upon information from only one cycle of the commercial real estate market. The first of these studies is Cole, Guilkey and Miles (1986), which examine 147 properties sold out of the NPI (formerly the Frank Russell Company, or FRC Index), during a period of rising prices from 1978 - 1984. These authors report that the average absolute difference in sales price and most recent independent appraisal was almost $9 \%$.

\footnotetext{
${ }^{1}$ Researchers also have generated indices based upon transactions. See Hoag (1980), Miles, Cole and Guilkey (1990), Webb, Miles and Guilkey (1992) and Fisher, Gatzlaff, Geltner and Haurin (2003). The MIT Center for Real Estate produces a commercial real estate index based upon transactions of NCREIF properties that covers 1984 to the present.
} 
Webb (1994) examines 569 properties sold out of the NPI during 1978 - 1992, including 152 sales prior to 1986 when CRE prices were rising, 115 sales during 1986 - 1987 when prices were flat, and 302 sales during 1988 - 1992 when prices were falling. This study finds that the absolute difference in sales price and most recent independent appraisal was $13 \%$ prior to 1986 , falling to $9 \%$ - $10 \%$ during $1986-1990$, and declining only $7 \%$ in $1991-1992$. It also finds that the simple difference in sales price and most recent appraisal was positive and significant during the time of rising prices, but negative and significant during times of falling prices, strong evidence of a lag in appraised values relative to market prices.

Fisher, Miles, and Webb (1999) is the most recent study to visit this issue, examining 2,739 properties sold from the NPI during its first twenty years, $1978-1998$. The authors report that the average absolute percentage error falls within a range of $9 \%-12.5 \%$, reaching the low end of the range during 1986 - 1987, when the commercial real estate market was transitioning from appreciation to depreciation. They also report that the average percentage error was $2.64 \%$ over the entire period but was positive during the up market and negative during the down market. The worst performance was during 1991, when sales were, on average, $13.4 \%$ below appraised values.

\section{Data and Methodology}

\subsection{Data:}

Our data come from the proprietary NCREIF property database. We collect information on quarterly appraised values, capital improvements and partial sales, as well as information on whether the appraisal was done in house or by an outside third-party appraiser. We collect fixed information on property characteristics, such as property type: office, retail, industrial, 
apartment, etc., and location. We collect the net and gross sales prices from the quarter in which the property was sold. We use the NCREIF National Property Indices to identify the cycles of the commercial real estate market.

We begin with 9,439 properties where data indicate that the property was sold during the period spanning 1982 Q1 through 2010 Q2. We limit our sample to the 8,281 sold properties that have been included in the NPI at some point during this period. Of these, we identify 7,575 as "true sales," which is defined by NCREIF as "full sale of the property." More than half of these sales have taken place since 1998 — the last year analyzed by Fisher, Miles and Webb (1999). We find that our initial sample includes only 3 sales in 1982 and 5 sales in 1983, too few for meaningful analysis, so we drop these properties (one office and seven industrials) from our sample. We also find that our initial sample includes 105 hotel properties, also too few for meaningful analysis on an annual basis, so we also exclude these from our analysis sample. This leaves us with 7,462 properties, of which 1,517 are apartments, 2,556 are industrial, 2,142 are office and 1,247 are retail.

We find that 63 properties have no quarterly appraisal data prior to the sale date and are excluded from the analysis, leaving 7,399 properties. When we examine the most recent appraised value prior to sale date, we find that the appraised value is exactly equal to net sales price for a large percentage of the sample. This happens when managers substitute the net sales price in place of the value from an actual appraisal. Consequently, we focus our attention on the second appraisal prior to sale date. This forces us to delete an additional 185 properties for which 
we have appraisal data for only one quarter prior to sale. ${ }^{2}$ This leaves us with our final analysis sample of 7,214 sales with data at least two quarters prior to sale.

Table 1A shows the number of properties and appraised value for the total NPI and for our annual samples of properties sold out of the NPI. During the sample period, the percentage of properties sold out of the NPI each year ranges from a low of 3.5\% in both 1984 and 1985 to a high of $17.2 \%$ in 1998 . There are two periods where annual sales exceed ten percent of the number of NPI properties_-during 1996 - 1999 and 2002 - 2007. There also are two periods where the value of annual sales exceeds ten percent of the value of the NPI portfolio-during $1996-1997$ and $2004-2005$.

As shown in Table 1B, our final sample consists of 2,085 office properties, 1,220 retail properties, 1,436 apartment properties, and 2,473 industrial properties. With the exception of 1985 and 1985, each year contains at least one percent of our sample, but this percentage rises dramatically in 1996 to more than four percent and reaches a peak in 2005 at more than ten percent of sales, before dropping dramatically in 2008. Similar trends are evident by property type.

The average property in our analysis sample of 7,214 was included in the NPI for only 17.4 quarters, with a median of 14 quarters. This average is shortest for apartments at 14.9 quarters and longest for industrials at 18.8 quarters, with office and retail coming in at 17.2 and 17.4 quarters, respectively.

\footnotetext{
${ }^{2}$ As we move to three and four quarters prior to sale, we lose an additional 242 and 209 properties, respectively, that have only two or three appraisals available prior to sale date.
} 


\subsection{Methodology}

Many properties report significant capital improvements during the four quarters prior to sale date. It is important to adjust appraisals occurring during these quarters to account for subsequent capital improvements; otherwise, we will observe large differences in the appraised values and subsequent sales prices that are attributable to these capital improvements rather than to appraisal error.

A second confounding effect is the capital appreciation that occurs during the four quarters prior to sale date. Without any adjustment, we would expect the appraised value to be less than or greater than sales price by the amount of capital appreciation during the period from appraisal date to sales date. This is especially important during quarters such as early 2009, when capital depreciation was in excess of five percent. To mitigate this effect, we calculate an alternative series of sales prices that are "rolled back" from the sales date to the appraisal date using the NPI capital appreciation for each property type and quarter. We present results for both the unadjusted and adjusted differences in sales price and appraised value.

To measure the accuracy of an appraisal, we calculate the difference in the appraised value and the subsequent transaction price.

Percentage Appraisal Error $_{i}$

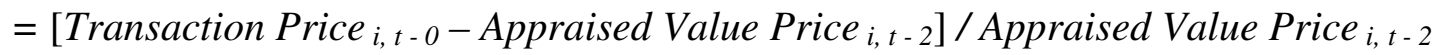

where:

Percentage Appraisal Error $_{i}$ is the percentage difference in the transaction price for property $i$ during quarter $t-0$ and the appraised value during quarter $t-2$; 
Appraised Value Price $_{i, t-2}$ is the appraised value for property $i$ during quarter $t-2$ preceding the sale of property $i$ during quarter $t-0$, adjusted for any capital improvements and partial sales recorded during quarter $t-1$; and

Transaction Price $_{i}$ is the transaction price for property $i$ during quarter $t-0$. $^{2}$

When we calculate the average percentage appraisal error, positive and negative values cancel out; this average provides a misleading indicator of accuracy for any single property. However, an investor in a portfolio of properties, such as a CREF, is interested in the value of the portfolio rather than in the values of individual properties in the portfolio; for such an investor, the average percentage appraisal error is informative for these investors. Similarly, investors interested in using an index such as the NPI are more concerned with the accuracy of the portfolio valuation than with the valuation of individual properties.

We also can use the average of this measure to determine if the appraised value is an unbiased predictor of sales price; if such is the case, then the average percentage appraisal error would be not significantly different from zero. Alternatively, if the appraised value is a biased predictor of sales price, as we would expect if appraisals lag true market values, then we would expect that the average percentage error is positive during periods of rising prices and negative during periods of falling prices, but may approximate zero during periods when prices are flat.

To better assess the accuracy of appraisals in predicting individual sales prices, we calculate an alternative measure of appraisal error - the absolute percentage appraisal error: Absolute Percentage Appraisal Error ${ }_{i}$ $=A B S\left[\right.$ Transaction Price $_{i, t-0}-$ Appraised Value Price $\left._{i, t-2}\right] /$ Appraised $_{\text {Value Price }}$ Apt $t-2_{2}$ where:

$A B S$ is the absolute-value operator, and other terms are as previously defined. 
Webb (1994) reports that the average absolute percentage appraisal error narrowed during the first 15 years of the NPI, whereas Fisher, Miles and Webb (1999) report that this measure actually widened during the 1990s. We provide new evidence regarding whether this trend continued, or was reversed during the most recent 10 years of the NPI.

We also examine the accuracy of "inside" appraisals relative to "outside" appraisals. Many property managers use their own staff to appraise properties in most quarters, and only hire out outside appraiser once per year. The NCREIF database includes a variable that identifies appraisals as "inside" or "outside" so we are able to distinguish between the two types of appraisals. $^{3}$

Finally, we will investigate determinants of the percentage appraisal error, both at the aggregate level and at the property level. First, we will construct quarterly time series of average percentage appraisal errors by averaging the percentage appraisal errors of properties that sell in each quarter. We then will estimate a regression model:

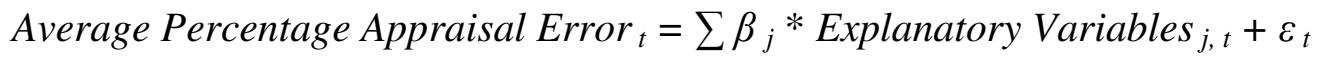

where:

Average Percentage Appraisal Error ${ }_{t}$ is the average percentage appraisal error as defined above for properties that sold during period $t$;

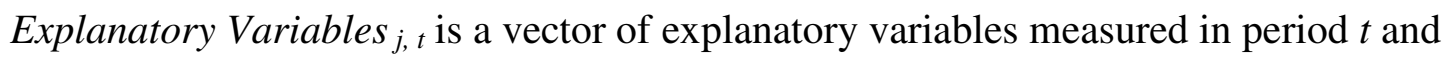
thought to explain the average percentage appraisal error in period $t$;

$\beta_{j}$ is the coefficient on explanatory variable $i$ and

$\varepsilon_{t}$ is a random error term.

\footnotetext{
${ }^{3}$ A number of managers do not appraise properties on a quarterly basis. The indicator variable for inside or outside appraisal also includes a third value indicating "no appraisal."
} 
The most important of our explanatory variables is the capital appreciation return on the NPI. We expect that the average percentage error is a positive function of the NPI appreciation return. We also include GDP, unemployment rate, the ten-year Treasury bond rate, and the national vacancy rate as explanatory variables.

We also will investigate the determinants of the percentage appraisal error at the property level.

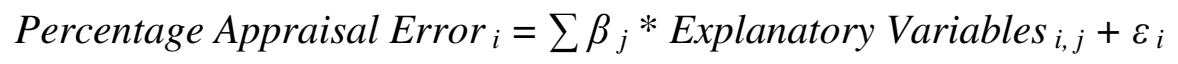

where:

Percentage Appraisal Error $_{i}$ is the difference in sales price and two-quarter prior appraised value, adjusted for capital gains, for property $i$;

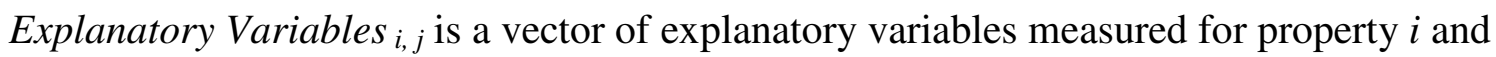
thought to explain the percentage appraisal error; $\beta_{j}$ is the coefficient on explanatory variable $j$ and $\varepsilon_{i}$ is a random error term.

\section{Results}

\subsection{Descriptive Statistics for the Equal-Weighted Percentage Difference}

Table 2A presents descriptive statistics for the equally weighted percentage differences in sales price and appraised values two quarters prior to the sale date calculated across all property types. Statistics are presented annually by date of appraisal on both an unadjusted and an adjusted basis, where the adjustment rolls back sales price by the percentage capital gain from time of the appraisal until the time of the next quarter. For each year, the table shows the median, 
mean, and standard error, as well as a t-statistic for the null hypothesis that the mean difference is zero, indicating that the appraisal is an unbiased estimate of the sales price.

For the full sample, the unadjusted median and average percentage differences are $2.8 \%$ and $4.9 \%$ respectively, indicating considerable positive skewness in the distribution. The t-statistic is 19.1 , indicating with high confidence that the true mean is significantly greater than zero, and meaning that the appraised value is a biased predictor of subsequent sales prices.

When we examine the annual differences, we find that the average for the full sample period hides considerable variability as the commercial real estate industry suffered through two massive down cycles, first during 1990 - 1995, and again during 2008 - 2010. During these down cycles, quarterly capital appreciation on the NPI was negative for at least nine consecutive quarters, cumulating to losses of $38.3 \%$ and $37.6 \%$, respectively (See Appendix Table 1 ). ${ }^{4}$ Also during each of these down cycles, the average annual differences in sales price and two-quarterprior appraisal were significantly negative, indicating that prices were significantly lower than prior appraisals. From 1988 through 1991, these differences were between $-4.7 \%$ and $-8.9 \%$ and each was statistically significant at better than the 0.01 level. For 2008 and 2009, the differences were $-12.9 \%$ and $-8.9 \%$, again statistically significant at better than the 0.01 level. We also see two periods where the average annual differences in sales price and two-quarter-prior appraisal were significantly positive, indicating that sales prices were significantly greater than prior appraisals. From 1996 through 1999, these differences were between 2.9\% and 9.8\%; from 2002 through 2007, these differences ranged between $3.4 \%$ and $14.7 \%$. Each of these differences is statistically significant at better than the 0.01 level.

\footnotetext{
${ }^{4}$ There also was a mild down cycle during 2001 - 2002, when losses cumulated to only $3.6 \%$. Interestingly, the losses during 2008 - 2010 almost exactly equal the $38.6 \%$ cumulative gain during $2004-2007$.
} 
In the right side of Table $2 \mathrm{~A}$ are the results where we adjust for capital gains during the period between the two-period-prior appraisal and the sales date. As we would expect, this adjustment reduces the magnitudes of the differences between sales price and two-quarter-prior appraisal, but does not qualitatively affect our findings based upon the unadjusted differences. We still find the same four periods where sales price significantly deviates from appraised values-the two "ups" and two "downs" in the market.

To summarize the results in Table 2A, we find strong evidence that the two-quarter prior appraised value is a biased estimate of sales price, that the direction of bias is downward in up markets but upward in down markets; and that the magnitude of the bias is greater in hotter and colder markets. This is consistent with the hypothesis that appraisals are lagged indicators of value and that they are not independent of prior appraisals.

Table $2 \mathrm{~B}$ presents descriptive statistics for the equal-weighted percentage difference in sales price and two-quarter-prior appraised value by property type, with adjustments for capital gains. For the full sample, the average percentage difference is largest for Retail and Apartment properties at $4.9 \%$ and is smallest for Industrial properties at $1.9 \%$, with Office properties in between at 3.7\%. Once again, however, the full-sample averages mask considerable variability, not only across years but also across property types. During 2009, for example, the average percentage difference for industrial properties was $-7.4 \%$ while that for Retail properties was $+5.2 \%$. During 2004 , the average percentage difference for Retail properties was $14.8 \%$ while that for Office properties was only 6.1\%. And during 1997, the average percentage difference for Retail properties was $6.6 \%$ while that for Office properties was $13.3 \%$. In general, there are large errors across the four property types. 


\subsection{Descriptive Statistics for the Value-Weighted Percentage Difference}

While the results in Tables $2 \mathrm{~A}$ and $2 \mathrm{~B}$ are valid for the valuations of individual properties, most institutional investors are more concerned with the results for portfolios of properties, where a larger property gets greater weight than a smaller property. In Tables $3 \mathrm{~A}$ and $3 \mathrm{~B}$, we recalculate the percentage differences in sales price and two-quarter-prior appraisals but weighting each property by its appraised value.

For the full sample across all property types, the unadjusted median and average percentage differences (shown in Table 3A) are $4.2 \%$ and $6.7 \%$, respectively, again indicating considerable positive skewness in the distribution. The t-statistic is 30.81 , indicating with high confidence that the true mean is significantly greater than zero, and meaning that the appraised value remains a biased predictor of subsequent sales prices. Moreover, the magnitude of the median and average percentage differences increased by statistically significant amounts. This is evidence that the bias in appraisals is greater for larger properties than for smaller properties.

The adjusted median and average percentage differences are $2.9 \%$ and $5.0 \%$, respectively, significantly smaller than the unadjusted value-weighted differences, but roughly double the comparable figures for the equally weighted percentage difference. Again, in Table 3, we see the same four episodes where sales price differs significantly from two-quarter-prior appraised value: 1990 - 1991 and 2008 - 2009, when sales prices were significantly lower than prior appraisals; and 1996 - 1998 and 2002 - 2007, when sales prices were significantly greater than prior appraisals.

In summary, the results in Table $3 \mathrm{~A}$ for the value-weighted percentage difference in sales price and two-quarter appraised value provide even stronger evidence of bias and appraisal lag 
than do the results for the equally weighted percentage difference that appear in Table 2A. Sales prices lead appraisals in both hot and cold markets.

We also point out that our results for 1995 - 1998 are largely consistent with those reported by Fisher, Miles and Webb (1999). Like us, they find that value-weighted percentage differences in sales price and prior appraised value were negative during 1988 - 1991 and positive during 1996 - 1998; however, they do not provide formal test statistics for ascertaining whether or not their differences are statistical significance. Our results provide this statistical evidence and show similar findings for the period from 1999 - 2010, but with differences almost double in magnitude.

In Table 3B, we break down the value-weighted results by property type, as we did in Table 2B for equal-weighted results.

\subsection{Descriptive Statistics for the Equal-Weighted Absolute Percentage Difference}

As damaging as are the results in Tables 2 and 3 for the accuracy of commercial real estate appraisals, the results in those two tables are based upon the average signed percentage difference, where positives and negatives cancel each other out, as they would in a portfolio context. In this section and the next, we analyze descriptive statistics for the absolute percentage difference, which provides a much better measure of the accuracy of an appraisal on an individual property. These results are even more damaging to the accuracy of commercial real estate appraisals.

Table 4A presents descriptive statistics for the equally weighted absolute percentage difference in sales price and two-quarter prior appraised value, adjusted for capital gains between the appraisal date and subsequent quarter returns and calculated across all property types. For the 
full sample, the median and average absolute percentage differences are $8.0 \%$ and $12.4 \%$. While t-statistics are inappropriate for testing the distribution of this variable, which is bounded on the left by zero, they are still instructive. For the full sample, the t-statistic is 60.7 , indicating that the mean is measured with high precision. The average absolute deviation of $12.4 \%$ is relatively close to the $10.8 \%$ statistic reported by Fisher, Miles and Webb (1999) for the 1980 - 1998 period.

Once again, however, the average over the full sample period masks considerable variability across sub-periods. The absolute difference was in single digits during $1984-1986$ and again during 1999 - 2001. The absolute difference peeks during the $2004-2006$ period, when it is consistently in excess of $16 \%$. There is considerable skew in the distribution, as evidenced by the difference in the mean and median; however, the median absolute difference also reaches double digits during the 2004 - 2006 bubble years and again during the $2008-2009$ crisis years.

Table 4B breaks down the results for the equally weighted absolute percentage difference by property type. Over the full sample period, the average absolute percentage difference is greatest for Office properties at $13.4 \%$ and smallest for Apartment properties at $10.9 \%$. In general, each of the four property types tracks the overall differences for all properties, with correlations ranging from 0.63 for Apartment properties to 0.86 for Industrial properties.

\subsection{Descriptive Statistics for the Value-Weighted Absolute Percentage Difference}

Table 5A presents descriptive statistics for the value-weighted absolute percentage difference in sales price and two-quarter prior appraised value, without and with adjustments for capital gains between the appraisal date and subsequent quarter returns. Without adjusting for 
capital gains, the median and mean differences are $8.6 \%$ and $13.3 \%$, respectively; with adjustments for capital gains, the median and mean differences fall to $7.7 \%$ and $12.3 \%$, respectively. The worst results are for 2004 - 2006 and 2008 - 2009, when the median reached double digits. In general, the results for the value-weighted absolute percentage difference are very similar to those for the equal-weighted absolute percentage difference, indicating that there is little difference in this measure of appraisal accuracy for large and small properties sold from the NPI.

Table 5B breaks down the results for the value-weighted absolute percentage difference by property type. Over the full sample period, the average absolute percentage difference is greatest for Office properties at $13.8 \%$ and smallest for Apartment properties at $10.9 \%$. In general, there are few differences from the equal-weighted results in Table 4B. As with the equal-weighted results, each of the four property types tracks the overall differences for all properties, with correlations ranging from 0.62 for Apartment properties to 0.85 for Office properties.

\subsection{Descriptive Statistics for Internal versus External Appraisals}

One potential (and likely) explanation for the poor appraisal accuracy documented thus far is the simple fact that most property managers do not pay for an external "third-party" appraisal each quarter. Most managers perform such an appraisal only once per year, relying upon internal appraisals or no appraisals (where they simply carry forward the most recent appraised value, adjusting for capital improvements and partial sales) during interim quarters.

We investigate this potential explanation in Table 6A, where we split our sample of sold properties into these three groups and recalculate the percentage difference in sales price and 
two-quarter-prior appraised value. As shown in Table 6A, about half of our sold properties had no appraisal two quarters prior to sale, and about one quarter had internal appraisals and one quarter had external appraisals.

We expect to find that the average percentage difference is smaller for external appraisals than for internal appraisal and smaller for internal appraisals than for no appraisals. In fact, this is exactly what we find. The median percentage difference rises from $1.0 \%$ for external appraisals to $1.6 \%$ for internal appraisals and then to $4.2 \%$ for no appraisals. The mean percentage difference rises from $1.9 \%$ for external appraisals to $3.0 \%$ for internal appraisals and then to $7.5 \%$ for no appraisals. These results appear on their face to be encouraging: most of the bias documented in Table 2 is attributable to the lag in time between the most recent "real" appraisal and the sale date. When either an internal or external appraisal was conducted, the bias decreases by more than two-thirds. This suggests that, in a portfolio context, appraisals are relatively accurate.

However, when we examine the percentage differences across time, our hopes are disappointed. For appraisals to be accurate in a portfolio context, pluses and minuses should cancel out across properties at the same point in time, not just across different points in time. What we see is that appraisal errors appear to be highly correlated across time and appear to lag changes in true market values. For example, the average percentage error for external appraisals plummets to $-17.5 \%$ in 1990 and to $-23.0 \%$ in 2008 , but balloons to $15.2 \%$ in 2006 .

Next, we look at the equal-weighted absolute percentage difference by appraisal type. This gives us our best measure of appraisal accuracy for an individual property. For the full sample period across all property types, we find that the median absolute percentage error for external appraisals is $7.9 \%$, which is slightly better than the $8.5 \%$ observed for no appraisals, but 
slightly worse than the $7.0 \%$ observed for inside appraisals. When we look at the mean, external, internal and no appraisals come in at $11.6 \%, 11.3 \%$ and $13.3 \%$, respectively. Hence, we find that external appraisals are no more accurate than inside appraisals and only slightly better than no update of the previous appraisal. All three are off by double digits.

Things are even worse when we look year by year. For external appraisals, the median absolute error is $16.0 \%$ for 2009 and the average is $19.3 \%$. Both figures are appreciably worse than the comparable figures for inside or no appraisals. The average absolute error is greater than $10 \%$ in each year from 2002 - 2009 with the exception of 2007 , when it was $9.0 \%$.

\subsection{Determinants of the Average Percentage Appraisal Error}

In Table 7, we present the results from ordinary-least-squares regression where the dependent variable is the quarterly average percentage difference in the sales price and twoquarter prior appraisal (equally weighted and adjusted for capital gains) and the explanatory variables are component returns of the NCREIF National Property Index and/or miscellaneous macro-economic variables, including GDP growth, change in the unemployment rate and the 10Year Treasury Bond Rate.

Our primary hypothesis is that appraisals lag true market values, so that the quarterly average percentage appraisal error should be inversely related to contemporaneous NPI returns. As shown in Panel A of Table 7, our results provide strong support for this hypothesis. The coefficient on the quarterly NPI total return is positive and highly significant ( $\mathrm{t}$-statistic $=5.09$ ) over the full sample period, which spans 106 quarters from 1984 - 2009, and explains 19 percent of the variability in the quarterly appraisal error. We also break our full sample period down into three subsamples, one for each decade. We find no relation between the NPI total return and the 
appraisal error prior to 1990 . From 1990 - 1999, the relation becomes highly significant with a coefficient of 1.05 , and explains 22 percent of the variability in the quarterly appraisal error during this period. From 2000 - 2009, the relation becomes even stronger, with a coefficient of 1.37, and explains 33 percent of the variability in quarterly appraisal error during this period.

In Panel B of Table 7, we investigate whether the explanatory power of the NPI total return series is solely a function of the capital appreciation component or also derives in part from the income return component. As expected, we find that the coefficient on appreciation return is positive and highly significant, but it explains only 17 percent of the variability in the quarterly appraisal error. When we analyze the income return, we also find a positive and highly significant coefficient that explains more than nine percent of the variability in the quarterly appraisal error. Finally, we include both return components in a single regression model; here, both coefficients remain positive and highly significant. Moreover, the explanatory power of the two components, at 23 percent of the variability in quarterly appraisal error, exceeds that of the NPI total return series. Hence, our evidence strongly suggests that the appraisal error is driven not only by the magnitude of capital appreciation but also by the magnitude of income return.

Finally, in Panel C of Table 7, we investigate whether the explanatory power of the NPI Total Return series is merely a spurious correlation with traditional macro-economic variables. First, we test the ability of three prominent macro variables in explaining the appraisal error, and then test whether the explanatory power of the NPI Total Return series disappears when included in a model with these macro variables. We find that each of the three macro variables is statistically significant in explaining the quarterly appraisal error. Errors are large when GDP growth is higher, when the change in unemployment is negative and when Treasury rates are lower. When we add the NPI Total Return to a model including these three macro variables, its 
coefficient drops from 1.14 to 0.75 , but remains highly significant with a t-statistic of 3.78 .

Moreover, this model explains 52 percent of the variability in the quarterly appraisal error. Hence, it appears that the explanatory power of the NPI Total Return is not simply the result of a spurious correlation with macro-economic factors.

\subsection{Determinants of the Percentage Appraisal Error}

Finally, we investigate determinants of the percentage appraisal error at the property

level. In Table 8, we present the results from a series of weighted least squares regressions where the dependent variable is the percentage difference in sales price and two-quarter-prior appraised value (adjusted for capital gains) and the explanatory variables include a set of macro-economic variables, a set of property variables and a set of dummy variables for year of appraisal. The regression weight is the appraised value, so as to value-weight the results.

In our first model, we include only the two components of the NPI return series, appreciation return and income return. At the property level, the appreciation return, but not the income return, is statistically significant; it explains almost seven percent of the variability in the percentage appraisal error, and its coefficient indicates that, for each one percentage point increase in the NPI Appreciation Return, the appraisal error increased by roughly two percentage points.

In our second model, we include our three macro-economic variables from Table 8 Change in the Unemployment Rate, GDP Growth and the 10-Year Treasury Rate. Both the Change in the Unemployment Rate and the 10-Year Treasury Rate are negative and highly significant. A one percentage point increase in the unemployment rate is associated with a roughly one percentage point decrease in the percentage appraisal error and a one percentage 
point increase in the Treasury Rate is associated with a $1.6 \%$ decrease in the percentage appraisal error. Together, our three macro variables explain 6.6 percent of the variability in the percentage appraisal error.

In our third model, we include a set of six property/appraisal characteristics-indicators for External Appraisal, Internal Appraisal, Levered properties, and property types (Office, Retail and Apartment). The omitted categories are No Appraisal, Unlevered properties and Industrial properties so the coefficients should be interpreted as differences from these types of properties. Of the six variables, only Retail lacks statistical significance. For Internal and External Appraisals, the percentage appraisal error is lower by 4.5 and 5.2 percentage points, respectively. For Levered properties, the percentage appraisal error is higher by 4.6 percentage points. For Office and Apartment properties, the percentage appraisal error is higher by 2.3 and 2.9 percentage points, respectively. Together, these six variables explain only four percent of the variability in the percentage appraisal error.

In our fourth model, we include each of the explanatory variables that enter into our first three models. Each of the variables significant in the first three models remains significant in this fourth model with the same signs, although the magnitude of many coefficients decrease. In addition, both the NPI Income Return and GDP Growth attain statistical significance. Overall, this model specification explains 11.9 percent of the variability in the percentage appraisal error.

In our sixth model, we include a series of dummy variables for each year in which the sold property was appraised, from 1990 through 2009. We exclude 1984 through 1989 because the results in Table 7 and additional property-level tests indicate that none of these coefficients are statistically significant. Ten of the year dummies are statistically significant at better than the 0.01 level, and their coefficient are largely consistent with the univariate results shown in 
Table 3. The percentage appraisal error was -9.4 percent in 1990, -6.5 percent in 1991 , and -16.2 percent in 2008, and was greater than ten percent in 2004, 2005 and 2006. Together, this set of year dummies explains 14.7 percent of the variability in of the percentage appraisal error.

In our seventh and final model, we add the year dummies from our sixth model to the property and macro variables that appear in our fifth model. Here we want to see how much of the explanatory power of the year dummies is "soaked up" by the macro variables. Our results show that the macro variables absorb much, but by no means all, of the explanatory power of the year dummies. Coefficients for most of the year dummies significant in our sixth model decrease in magnitude, and most lose statistical significance; only two year dummies (2006 and 2008) remain statistically significant at better than the 0.01 level. Both the NPI Appreciation Return and Income Return remain statistically significant, and the coefficient on the Income Return increases by almost tenfold. GDP growth loses significance and the Treasury Rate almost does so. Overall, this model explains $17.3 \%$ of the variability in the percentage appraisal error. In general, the small increase in explanatory power and large drop in t-statistics indicate that multicollinearity is at play in this specification so it should be discounted accordingly.

\section{Summary and Conclusions}

In this study, we have analyzed the accuracy of commercial real estate appraisals using data from properties sold out of the NCREIF National Property Index during the last 25 years. Our findings are sobering. On average, appraisals are more than $10 \%$ above, or below, subsequent sales prices, and this results holds true for both external and internal appraisals. Even in a portfolio context where errors can cancel each other out, results are not appreciably better; appraisals are off by an average of $5 \%$ of value because the under- and over-valuations are 
highly correlated across properties at the same points in time. In other words, errors don't "average out." We also find that appraisals appear to lag the true sales prices, falling below in hot markets and remaining above in cold markets. The largest deviations are observed during the two peaks and two valleys of the past two cycles in the commercial real estate market. Not surprisingly, the worst performance occurred during the recent financial crisis. 


\section{References}

Cole, Rebel, David Guilkey and Mike Miles. 1986. Toward an Assessment of the Reliability of Commercial Appraisals. The Appraisal Journal, July, 442 - 432.

Fisher, Jeffery D., Dean Gatzlaff, David Geltner and Donald Haurin. 2004. An Analysis of the Determinants of Transaction Frequency of Institutional Commercial Real Estate Investment Property. Real Estate Economics 32 (2), 239 - 264.

Fisher, Jeffery D., Mike E. Miles and R. Brian Webb. 1999. How Reliable Are Commercial Appraisals? Another Look. Real Estate Finance, Fall, 9 - 15.

Hoag, James W. 1980. Towards Indices of Real Estate Value and Return. The Journal of Finance 35, 569 - 580.

Miles, Mike, Rebel Cole and David Guilkey. 1990. A Different Look at Commercial Real Estate Returns. AREUEA Journal 18, 403 - 430.

Miles, Mike, David Guilkey, Brian Webb and Kevin Hunter. 1991. An Empirical Evaluation of the Reliability of Commercial Appraisals, 1978 - 1990. NCREIF Working Paper.

Webb, R. Brian. 1994. On the Reliability of Commercial Appraisals: An Analysis of Properties Sold from the Russell-NCREIF Index (1978 - 1992), Real Estate Finance 11 (1), 62 - 65.

Webb, R. Brian, Mike E. Miles, and David K. Guilkey. 1992. Transactions-Driven Commercial Real Estate Returns: The Panacea to Asset Allocation Models? AREUEA Journal 20(2), 325 357. 


\section{Appendix Table 1: \\ NPI Returns 1980 - 2010}

This table presents returns on the NCREIF National Property Index over the period 1980 Q1 through 2010 Q2. Total return, income return and appreciation return are shown for each quarter.

\begin{tabular}{|c|c|c|c|c|c|c|c|c|c|c|c|}
\hline Year-Qtr & Total & Income & Appreciation & Year-Qtr & Total & Income & Appreciation & Year-Qtr & Total & Income & Appreciation \\
\hline 1980Q1 & $5.5 \%$ & $2.1 \%$ & $3.5 \%$ & 1990Q1 & $1.4 \%$ & $1.6 \%$ & $-0.2 \%$ & 2000Q1 & $2.4 \%$ & $2.0 \%$ & $0.4 \%$ \\
\hline 1980Q2 & $2.4 \%$ & $2.1 \%$ & $0.3 \%$ & 1990Q2 & $1.5 \%$ & $1.6 \%$ & $-0.1 \%$ & 2000Q2 & $3.1 \%$ & $2.1 \%$ & $0.9 \%$ \\
\hline 1980Q3 & $3.8 \%$ & $2.0 \%$ & $1.8 \%$ & 1990Q3 & $0.8 \%$ & $1.6 \%$ & $-0.7 \%$ & 2000Q3 & $2.9 \%$ & $2.1 \%$ & $0.8 \%$ \\
\hline 1980Q4 & $5.3 \%$ & $2.0 \%$ & $3.3 \%$ & 1990Q4 & $-1.4 \%$ & $1.7 \%$ & $-3.1 \%$ & 2000Q4 & $3.3 \%$ & $2.1 \%$ & $1.2 \%$ \\
\hline 1981Q1 & $3.0 \%$ & $1.9 \%$ & $1.0 \%$ & 1991Q1 & $0.0 \%$ & $1.6 \%$ & $-1.6 \%$ & 2001Q1 & $2.4 \%$ & $2.1 \%$ & $0.3 \%$ \\
\hline 1981Q2 & $4.2 \%$ & $2.1 \%$ & $2.2 \%$ & 1991Q2 & $0.0 \%$ & $1.7 \%$ & $-1.7 \%$ & 2001Q2 & $2.5 \%$ & $2.1 \%$ & $0.3 \%$ \\
\hline 1981Q3 & $3.2 \%$ & $1.9 \%$ & $1.3 \%$ & 1991Q3 & $-0.3 \%$ & $1.6 \%$ & $-2.0 \%$ & 2001Q3 & $1.6 \%$ & $2.1 \%$ & $-0.5 \%$ \\
\hline 1981Q4 & $5.3 \%$ & $1.9 \%$ & $3.4 \%$ & 1991Q4 & $-5.3 \%$ & $1.7 \%$ & $-7.0 \%$ & 2001Q4 & $0.7 \%$ & $2.1 \%$ & $-1.4 \%$ \\
\hline 1982Q1 & $2.5 \%$ & $1.9 \%$ & $0.6 \%$ & 1992Q1 & $0.0 \%$ & $1.8 \%$ & $-1.8 \%$ & 2002Q1 & $1.5 \%$ & $2.1 \%$ & $-0.6 \%$ \\
\hline 1982Q2 & $2.1 \%$ & $1.9 \%$ & $0.1 \%$ & 1992Q2 & $-1.0 \%$ & $1.9 \%$ & $-2.9 \%$ & 2002Q2 & $1.6 \%$ & $2.1 \%$ & $-0.5 \%$ \\
\hline 1982Q3 & $1.5 \%$ & $1.9 \%$ & $-0.4 \%$ & 1992Q3 & $-0.4 \%$ & $1.8 \%$ & $-2.3 \%$ & 2002Q3 & $1.8 \%$ & $2.0 \%$ & $-0.2 \%$ \\
\hline 1982Q4 & $3.0 \%$ & $2.0 \%$ & $1.1 \%$ & 1992Q4 & $-2.8 \%$ & $1.9 \%$ & $-4.7 \%$ & 2002Q4 & $1.7 \%$ & $2.0 \%$ & $-0.3 \%$ \\
\hline 1983Q1 & $1.8 \%$ & $2.0 \%$ & $-0.3 \%$ & 1993Q1 & $0.8 \%$ & $2.0 \%$ & $-1.2 \%$ & 2003Q1 & $1.9 \%$ & $2.0 \%$ & $-0.1 \%$ \\
\hline 1983Q2 & $2.5 \%$ & $2.0 \%$ & $0.6 \%$ & 1993Q2 & $-0.2 \%$ & $1.9 \%$ & $-2.2 \%$ & 2003Q2 & $2.1 \%$ & $2.0 \%$ & $0.1 \%$ \\
\hline 1983Q3 & $3.0 \%$ & $1.9 \%$ & $1.1 \%$ & 1993Q3 & $1.1 \%$ & $2.0 \%$ & $-0.9 \%$ & 2003Q3 & $2.0 \%$ & $1.9 \%$ & $0.1 \%$ \\
\hline 1983Q4 & $5.3 \%$ & $1.8 \%$ & $3.5 \%$ & 1993Q4 & $-0.3 \%$ & $2.1 \%$ & $-2.3 \%$ & 2003Q4 & $2.8 \%$ & $1.9 \%$ & $0.9 \%$ \\
\hline 1984Q1 & $3.4 \%$ & $1.8 \%$ & $1.5 \%$ & 1994Q1 & $1.3 \%$ & $2.1 \%$ & $-0.7 \%$ & 2004Q1 & $2.6 \%$ & $1.8 \%$ & $0.7 \%$ \\
\hline 1984Q2 & $3.2 \%$ & $1.9 \%$ & $1.3 \%$ & 1994Q2 & $1.5 \%$ & $2.1 \%$ & $-0.6 \%$ & 2004Q2 & $3.1 \%$ & $1.8 \%$ & $1.3 \%$ \\
\hline 1984Q3 & $2.5 \%$ & $1.8 \%$ & $0.6 \%$ & 1994Q3 & $1.5 \%$ & $2.1 \%$ & $-0.6 \%$ & 2004Q3 & $3.4 \%$ & $1.8 \%$ & $1.6 \%$ \\
\hline 1984Q4 & $4.2 \%$ & $1.9 \%$ & $2.4 \%$ & 1994Q4 & $1.9 \%$ & $2.2 \%$ & $-0.3 \%$ & 2004Q4 & $4.7 \%$ & $1.8 \%$ & $2.9 \%$ \\
\hline 1985Q1 & $2.1 \%$ & $1.8 \%$ & $0.3 \%$ & 1995Q1 & $2.1 \%$ & $2.2 \%$ & $-0.1 \%$ & 2005Q1 & $3.5 \%$ & $1.7 \%$ & $1.8 \%$ \\
\hline 1985Q2 & $2.6 \%$ & $1.9 \%$ & $0.7 \%$ & 1995Q2 & $2.1 \%$ & $2.2 \%$ & $-0.2 \%$ & 2005Q2 & $5.3 \%$ & $1.7 \%$ & $3.7 \%$ \\
\hline 1985Q3 & $2.4 \%$ & $1.9 \%$ & $0.5 \%$ & 1995Q3 & $2.1 \%$ & $2.2 \%$ & $-0.1 \%$ & 2005Q3 & $4.4 \%$ & $1.6 \%$ & $2.8 \%$ \\
\hline 1985Q4 & $3.7 \%$ & $1.8 \%$ & $2.0 \%$ & 1995Q4 & $1.1 \%$ & $2.2 \%$ & $-1.1 \%$ & 2005Q4 & $5.4 \%$ & $1.6 \%$ & $3.8 \%$ \\
\hline 1986Q1 & $2.0 \%$ & $1.8 \%$ & $0.2 \%$ & 1996Q1 & $2.4 \%$ & $2.1 \%$ & $0.3 \%$ & 2006Q1 & $3.6 \%$ & $1.5 \%$ & $2.1 \%$ \\
\hline 1986Q2 & $2.0 \%$ & $1.9 \%$ & $0.1 \%$ & 1996Q2 & $2.3 \%$ & $2.2 \%$ & $0.1 \%$ & 2006Q2 & $4.0 \%$ & $1.5 \%$ & $2.5 \%$ \\
\hline 1986Q3 & $1.5 \%$ & $1.8 \%$ & $-0.3 \%$ & 1996Q3 & $2.6 \%$ & $2.1 \%$ & $0.5 \%$ & 2006Q3 & $3.5 \%$ & $1.5 \%$ & $2.0 \%$ \\
\hline 1986Q4 & $2.6 \%$ & $1.8 \%$ & $0.8 \%$ & 1996Q4 & $2.6 \%$ & $2.1 \%$ & $0.5 \%$ & 2006Q4 & $4.5 \%$ & $1.5 \%$ & $3.0 \%$ \\
\hline 1987Q1 & $1.8 \%$ & $1.8 \%$ & $0.1 \%$ & 1997Q1 & $2.3 \%$ & $2.1 \%$ & $0.2 \%$ & 2007Q1 & $3.6 \%$ & $1.4 \%$ & $2.2 \%$ \\
\hline 1987Q2 & $1.2 \%$ & $1.8 \%$ & $-0.6 \%$ & 1997Q2 & $2.8 \%$ & $2.2 \%$ & $0.6 \%$ & 2007Q2 & $4.6 \%$ & $1.4 \%$ & $3.2 \%$ \\
\hline 1987Q3 & $2.1 \%$ & $1.8 \%$ & $0.3 \%$ & 1997Q3 & $3.4 \%$ & $2.2 \%$ & $1.2 \%$ & 2007Q3 & $3.6 \%$ & $1.3 \%$ & $2.2 \%$ \\
\hline 1987Q4 & $2.7 \%$ & $1.8 \%$ & $0.9 \%$ & 1997Q4 & $4.7 \%$ & $2.2 \%$ & $2.5 \%$ & 2007Q4 & $3.2 \%$ & $1.3 \%$ & $1.9 \%$ \\
\hline 1988Q1 & $1.8 \%$ & $1.7 \%$ & $0.1 \%$ & 1998Q1 & $4.1 \%$ & $2.2 \%$ & $1.9 \%$ & 2008Q1 & $1.6 \%$ & $1.3 \%$ & $0.3 \%$ \\
\hline 1988Q2 & $2.0 \%$ & $1.8 \%$ & $0.2 \%$ & 1998Q2 & $4.2 \%$ & $2.1 \%$ & $2.1 \%$ & 2008Q2 & $0.6 \%$ & $1.3 \%$ & $-0.7 \%$ \\
\hline 1988Q3 & $2.4 \%$ & $1.7 \%$ & $0.7 \%$ & 1998Q3 & $3.5 \%$ & $2.1 \%$ & $1.4 \%$ & 2008Q3 & $-0.2 \%$ & $1.2 \%$ & $-1.4 \%$ \\
\hline 1988Q4 & $3.1 \%$ & $1.7 \%$ & $1.4 \%$ & 1998Q4 & $3.6 \%$ & $2.1 \%$ & $1.5 \%$ & 2008Q4 & $-8.3 \%$ & $1.3 \%$ & $-9.5 \%$ \\
\hline 1989Q1 & $1.8 \%$ & $1.7 \%$ & $0.1 \%$ & 1999Q1 & $2.6 \%$ & $2.0 \%$ & $0.6 \%$ & 2009Q1 & $-7.3 \%$ & $1.4 \%$ & $-8.7 \%$ \\
\hline 1989Q2 & $2.0 \%$ & $1.7 \%$ & $0.3 \%$ & 1999Q2 & $2.6 \%$ & $2.1 \%$ & $0.5 \%$ & 2009 Q2 & $-5.4 \%$ & $1.5 \%$ & $-6.9 \%$ \\
\hline 1989Q3 & $2.0 \%$ & $1.6 \%$ & $0.5 \%$ & 1999Q3 & $2.8 \%$ & $2.0 \%$ & $0.8 \%$ & 2009 Q3 & $-3.3 \%$ & $1.6 \%$ & $-4.9 \%$ \\
\hline \multirow[t]{3}{*}{ 1989Q4 } & $1.8 \%$ & $1.6 \%$ & $0.2 \%$ & 1999Q4 & $2.9 \%$ & $2.0 \%$ & $0.9 \%$ & 2009 Q4 & $-2.1 \%$ & $1.6 \%$ & $-3.7 \%$ \\
\hline & & & & & & & & 2010 Q1 & $0.8 \%$ & $1.7 \%$ & $-0.9 \%$ \\
\hline & & & & & & & & 2010 Q2 & $3.3 \%$ & $1.7 \%$ & $-0.8 \%$ \\
\hline
\end{tabular}




\section{Table 1A: \\ Properties Sold from the NPI \\ 1984 Q1 - 2010 Q2}

This table shows the number and value of all properties in the NCREIF NPI portfolio along with the number and value of properties sold out of the NPI portfolio during each year from 1984 Q1 -2010 Q2 and for which at least two quarterly appraisals are available prior to the sale date. Note that the statistics for 2010 are based upon only the first two quarters.

\begin{tabular}{|c|c|c|c|c|c|c|}
\hline \multirow[b]{2}{*}{ Period } & \multicolumn{2}{|c|}{ Total NPI } & \multicolumn{4}{|c|}{ Sold from NPI } \\
\hline & Number & $\begin{array}{c}\text { Value } \\
\text { (\$ Millions) }\end{array}$ & Number & Pct. & $\begin{array}{c}\text { Value } \\
\text { (\$ Millions) }\end{array}$ & Pct. \\
\hline $12 / 31 / 1983$ & 989 & $9,025.0$ & & & & \\
\hline $12 / 31 / 1984$ & 1,060 & $11,476.0$ & 37 & $3.5 \%$ & 186.5 & $1.6 \%$ \\
\hline $12 / 31 / 1985$ & 1,159 & $15,407.8$ & 41 & $3.5 \%$ & 139.8 & $0.9 \%$ \\
\hline $12 / 31 / 1986$ & 1,253 & $17,870.9$ & 90 & $7.2 \%$ & 541.8 & $3.0 \%$ \\
\hline $12 / 31 / 1987$ & 1,403 & $22,184.6$ & 86 & $6.1 \%$ & 598.1 & $2.7 \%$ \\
\hline $12 / 31 / 1988$ & 1,536 & $28,470.9$ & 118 & $7.7 \%$ & $1,324.1$ & $4.7 \%$ \\
\hline $12 / 31 / 1989$ & 1,660 & $32,656.1$ & 138 & $8.3 \%$ & $1,413.8$ & $4.3 \%$ \\
\hline $12 / 31 / 1990$ & 1,877 & $37,970.8$ & 109 & $5.8 \%$ & 799.8 & $2.1 \%$ \\
\hline $12 / 31 / 1991$ & 2,028 & $37,009.6$ & 106 & $5.2 \%$ & $1,322.7$ & $3.6 \%$ \\
\hline $12 / 31 / 1992$ & 2,233 & $39,499.3$ & 87 & $3.9 \%$ & 520.8 & $1.3 \%$ \\
\hline $12 / 31 / 1993$ & 2,069 & $40,949.9$ & 140 & $6.8 \%$ & $1,289.8$ & $3.1 \%$ \\
\hline $12 / 31 / 1994$ & 1,970 & $41,030.8$ & 165 & $8.4 \%$ & $1,766.0$ & $4.3 \%$ \\
\hline $12 / 31 / 1995$ & 2,322 & $48,278.5$ & 172 & $7.4 \%$ & $2,168.0$ & $4.5 \%$ \\
\hline $12 / 31 / 1996$ & 2,378 & $54,424.1$ & 307 & $12.9 \%$ & $4,147.7$ & $7.6 \%$ \\
\hline $12 / 31 / 1997$ & 2,560 & $66,134.9$ & 396 & $15.5 \%$ & $7,028.1$ & $10.6 \%$ \\
\hline $12 / 31 / 1998$ & 2,440 & $67,352.9$ & 420 & $17.2 \%$ & $10,533.5$ & $15.6 \%$ \\
\hline $12 / 31 / 1999$ & 2,628 & $81,989.1$ & 342 & $13.0 \%$ & $7,176.6$ & $8.8 \%$ \\
\hline $12 / 31 / 2000$ & 3,028 & $97,634.8$ & 283 & $9.3 \%$ & $8,432.2$ & $8.6 \%$ \\
\hline $12 / 31 / 2001$ & 3,509 & $113,708.9$ & 304 & $8.7 \%$ & $7,236.3$ & $6.4 \%$ \\
\hline $12 / 31 / 2002$ & 3,681 & $122,621.4$ & 372 & $10.1 \%$ & $9,179.1$ & $7.5 \%$ \\
\hline $12 / 31 / 2003$ & 4,060 & $133,107.2$ & 388 & $9.6 \%$ & $10,094.4$ & $7.6 \%$ \\
\hline $12 / 31 / 2004$ & 4,151 & $146,535.2$ & 580 & $14.0 \%$ & $16,913.7$ & $11.5 \%$ \\
\hline $12 / 31 / 2005$ & 4,712 & $189,614.2$ & 737 & $15.6 \%$ & $22,639.4$ & $11.9 \%$ \\
\hline $12 / 31 / 2006$ & 5,332 & $247,285.3$ & 602 & $11.3 \%$ & $18,574.2$ & $7.5 \%$ \\
\hline $12 / 31 / 2007$ & 5,713 & $310,068.4$ & 596 & $10.4 \%$ & $22,372.7$ & $7.2 \%$ \\
\hline $12 / 31 / 2008$ & 6,285 & $305,276.4$ & 230 & $3.7 \%$ & $9,384.5$ & $3.1 \%$ \\
\hline $12 / 31 / 2009$ & 6,209 & $238,227.5$ & 246 & $4.0 \%$ & $6,515.1$ & $2.7 \%$ \\
\hline $6 / 30 / 2010$ & 6,066 & $234,484.6$ & 122 & $2.0 \%$ & $4,261.8$ & $1.8 \mathrm{c}$ \\
\hline
\end{tabular}




\section{Table 1B: \\ Properties Sold from the NPI \\ 1984 Q1 - 2010 Q2}

This table shows the number of NPI properties sold during each year from 1984 Q1 - 2010 Q2 and for which at least two quarterly appraisals are available prior to the sale date. Separate statistics are presented for all properties and for office, retail, apartment and industrial properties. Not included in totals are 105 hotel properties that were excluded from the analysis. Note that the statistics for 2010 are based upon only the first two quarters.

\begin{tabular}{|c|c|c|c|c|c|c|c|c|c|c|}
\hline YEAR & \multicolumn{2}{|c|}{ TOTAL } & \multicolumn{2}{|c|}{ OFFICE } & \multicolumn{2}{|c|}{ RETAIL } & \multicolumn{2}{|c|}{ APT } & \multicolumn{2}{|c|}{ INDUS } \\
\hline 1984 & 37 & $0.5 \%$ & 17 & $0.8 \%$ & 8 & $0.7 \%$ & 0 & $0.0 \%$ & 12 & $0.5 \%$ \\
\hline 1985 & 41 & $0.6 \%$ & 7 & $0.3 \%$ & 6 & $0.5 \%$ & 1 & $0.1 \%$ & 27 & $1.1 \%$ \\
\hline 1986 & 90 & $1.2 \%$ & 23 & $1.1 \%$ & 23 & $1.9 \%$ & 2 & $0.1 \%$ & 42 & $1.7 \%$ \\
\hline 1987 & 86 & $1.2 \%$ & 25 & $1.2 \%$ & 18 & $1.5 \%$ & 1 & $0.1 \%$ & 42 & $1.7 \%$ \\
\hline 1988 & 118 & $1.6 \%$ & 24 & $1.2 \%$ & 21 & $1.7 \%$ & 7 & $0.5 \%$ & 66 & $2.7 \%$ \\
\hline 1989 & 138 & $1.9 \%$ & 41 & $2.0 \%$ & 22 & $1.8 \%$ & 6 & $0.4 \%$ & 69 & $2.8 \%$ \\
\hline 1990 & 109 & $1.5 \%$ & 42 & $2.0 \%$ & 7 & $0.6 \%$ & 3 & $0.2 \%$ & 57 & $2.3 \%$ \\
\hline 1991 & 106 & $1.5 \%$ & 40 & $1.9 \%$ & 12 & $1.0 \%$ & 7 & $0.5 \%$ & 47 & $1.9 \%$ \\
\hline 1992 & 87 & $1.2 \%$ & 25 & $1.2 \%$ & 16 & $1.3 \%$ & 8 & $0.6 \%$ & 38 & $1.5 \%$ \\
\hline 1993 & 140 & $1.9 \%$ & 42 & $2.0 \%$ & 25 & $2.0 \%$ & 33 & $2.3 \%$ & 40 & $1.6 \%$ \\
\hline 1994 & 165 & $2.3 \%$ & 40 & $1.9 \%$ & 17 & $1.4 \%$ & 36 & $2.5 \%$ & 72 & $2.9 \%$ \\
\hline 1995 & 172 & $2.4 \%$ & 55 & $2.6 \%$ & 33 & $2.7 \%$ & 29 & $2.0 \%$ & 55 & $2.2 \%$ \\
\hline 1996 & 307 & $4.3 \%$ & 96 & $4.6 \%$ & 58 & $4.8 \%$ & 51 & $3.6 \%$ & 102 & $4.1 \%$ \\
\hline 1997 & 396 & $5.5 \%$ & 93 & $4.5 \%$ & 94 & $7.7 \%$ & 74 & $5.2 \%$ & 135 & $5.5 \%$ \\
\hline 1998 & 420 & $5.8 \%$ & 121 & $5.8 \%$ & 99 & $8.1 \%$ & 71 & $4.9 \%$ & 129 & $5.2 \%$ \\
\hline 1999 & 342 & $4.7 \%$ & 94 & $4.5 \%$ & 92 & $7.5 \%$ & 59 & $4.1 \%$ & 97 & $3.9 \%$ \\
\hline 2000 & 283 & $3.9 \%$ & 93 & $4.5 \%$ & 59 & $4.8 \%$ & 56 & $3.9 \%$ & 75 & $3.0 \%$ \\
\hline 2001 & 304 & $4.2 \%$ & 75 & $3.6 \%$ & 58 & $4.8 \%$ & 94 & $6.5 \%$ & 77 & $3.1 \%$ \\
\hline 2002 & 372 & $5.2 \%$ & 96 & $4.6 \%$ & 62 & $5.1 \%$ & 89 & $6.2 \%$ & 125 & $5.1 \%$ \\
\hline 2003 & 388 & $5.4 \%$ & 115 & $5.5 \%$ & 73 & $6.0 \%$ & 87 & $6.1 \%$ & 113 & $4.6 \%$ \\
\hline 2004 & 580 & $8.0 \%$ & 159 & $7.6 \%$ & 94 & $7.7 \%$ & 108 & $7.5 \%$ & 219 & $8.9 \%$ \\
\hline 2005 & 735 & $10.2 \%$ & 216 & $10.4 \%$ & 153 & $12.5 \%$ & 161 & $11.2 \%$ & 205 & $8.3 \%$ \\
\hline 2006 & 602 & $8.3 \%$ & 183 & $8.8 \%$ & 49 & $4.0 \%$ & 147 & $10.2 \%$ & 223 & $9.0 \%$ \\
\hline 2007 & 596 & $8.3 \%$ & 200 & $9.6 \%$ & 60 & $4.9 \%$ & 130 & $9.1 \%$ & 206 & $8.3 \%$ \\
\hline 2008 & 232 & $3.2 \%$ & 77 & $3.7 \%$ & 15 & $1.2 \%$ & 65 & $4.5 \%$ & 75 & $3.0 \%$ \\
\hline 2009 & 246 & $3.4 \%$ & 57 & $2.7 \%$ & 19 & $1.6 \%$ & 80 & $5.6 \%$ & 90 & $3.6 \%$ \\
\hline 2010 & 122 & $1.7 \%$ & 29 & $1.4 \%$ & 27 & $2.2 \%$ & 31 & $2.2 \%$ & 35 & $1.4 \%$ \\
\hline
\end{tabular}

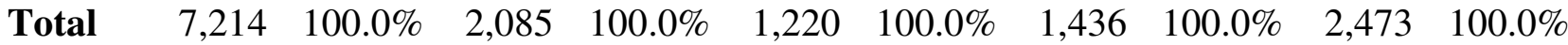


Table 2A

Equally Weighted Percentage Difference in Sales Price and Appraised Value

This table presents statistics for the equally weighted percentage difference in sales price and appraised values two quarters prior to the sale date. Statistics are presented annually by date of appraisal on both an unadjusted and an adjusted basis, where the adjustment rolls back sales price by the percentage capital gain from time of the appraisal until the time of the next quarter. For each year, the table shows the median, mean, and standard error, as well as a t-statistic for the null hypothesis that the mean difference is zero, indicating that the appraisal is an unbiased estimate of the sales price. *,**, and $* * *$ indicate that the mean is statistically different from zero at the $0.10,0.05$ and 0.01 levels, respectively.

\section{Unadjusted for Capital Gains}

Year Obs. Median Mean S.E. t-Stat

$\begin{array}{lrrrrrrrrr}\text { Total } & 7,214 & 2.8 \% & 4.9 \% & 0.3 \% & 19.1 * * * & 1.4 \% & 3.5 \% & 0.2 \% & 14.0 * * * \\ \mathbf{1 9 8 4} & 44 & -6.7 \% & -4.4 \% & 1.3 \% & -3.4 * * * & -8.7 \% & -6.4 \% & 1.3 \% & -4.9 * * * \\ \mathbf{1 9 8 5} & 37 & 0.6 \% & 0.7 \% & 1.7 \% & 0.4 & -0.8 \% & -1.0 \% & 1.7 \% & -0.6 \\ \mathbf{1 9 8 6} & 120 & 0.3 \% & 0.3 \% & 1.1 \% & 0.2 & -1.1 \% & -1.2 \% & 1.1 \% & -1.1 \\ \mathbf{1 9 8 7} & 93 & -1.4 \% & -0.9 \% & 1.9 \% & -0.5 & -2.8 \% & -1.9 \% & 1.8 \% & -1.0 \\ \mathbf{1 9 8 8} & 125 & -4.4 \% & -4.7 \% & 1.6 \% & -2.9 * * * & -5.6 \% & -6.1 \% & 1.6 \% & -3.9 * * * \\ \mathbf{1 9 8 9} & 121 & -3.8 \% & -5.9 \% & 1.5 \% & -4.0 * * * & -4.9 \% & -7.0 \% & 1.4 \% & -4.9 * * * \\ \mathbf{1 9 9 0} & 136 & -6.5 \% & -8.9 \% & 1.1 \% & -8.2 * * * & -7.1 \% & -9.5 \% & 1.1 \% & -9.0 * * * \\ \mathbf{1 9 9 1} & 69 & -6.3 \% & -7.3 \% & 1.5 \% & -5.0 * * * & -5.3 \% & -6.1 \% & 1.5 \% & -4.2 * * * \\ \mathbf{1 9 9 2} & 111 & -2.1 \% & -2.9 \% & 1.6 \% & -1.8 * & 0.4 \% & -1.2 \% & 1.7 \% & -0.7 \\ \mathbf{1 9 9 3} & 149 & 0.0 \% & -2.5 \% & 1.3 \% & -2.0 * * & 0.7 \% & -1.4 \% & 1.3 \% & -1.0 \\ \mathbf{1 9 9 4} & 197 & 0.1 \% & 0.5 \% & 1.5 \% & 0.3 & 0.8 \% & 0.4 \% & 1.5 \% & 0.2 \\ \mathbf{1 9 9 5} & 173 & 0.3 \% & 1.5 \% & 3.6 \% & 0.4 & -0.1 \% & 0.8 \% & 3.6 \% & 0.2 \\ \mathbf{1 9 9 6} & 393 & 1.4 \% & 4.1 \% & 1.0 \% & 3.9 * * * & 0.4 \% & 3.2 \% & 1.0 \% & 3.1 * * * \\ \mathbf{1 9 9 7} & 403 & 5.3 \% & 9.8 \% & 1.8 \% & 5.3 * * * & 3.7 \% & 8.1 \% & 1.8 \% & 4.5 * * * \\ \mathbf{1 9 9 8} & 409 & 5.5 \% & 7.6 \% & 0.7 \% & 10.2 * * * & 2.3 \% & 4.4 \% & 0.7 \% & 6.2 * * * \\ \mathbf{1 9 9 9} & 268 & 1.6 \% & 2.9 \% & 0.7 \% & 4.4 * * * & 0.1 \% & 1.3 \% & 0.7 \% & 1.9 * \\ \mathbf{2 0 0 0} & 317 & 0.6 \% & 2.5 \% & 1.4 \% & 1.8 * & -0.9 \% & 1.0 \% & 1.3 \% & 0.7 \\ \mathbf{2 0 0 1} & 310 & 0.8 \% & 1.7 \% & 0.7 \% & 2.3 * * & 0.1 \% & 0.6 \% & 0.7 \% & 0.8 \\ \mathbf{2 0 0 2} & 383 & 2.1 \% & 3.4 \% & 0.7 \% & 4.6 * * * & 2.3 \% & 3.5 \% & 0.7 \% & 4.8 * * * \\ \mathbf{2 0 0 3} & 456 & 4.1 \% & 4.8 \% & 0.8 \% & 6.1 * * * & 3.7 \% & 4.3 \% & 0.8 \% & 5.5 * * * \\ \mathbf{2 0 0 4} & 717 & 11.6 \% & 12.0 \% & 0.7 \% & 17.1 * * * & 9.8 \% & 10.1 \% & 0.7 \% & 14.8 * * * \\ \mathbf{2 0 0 5} & 697 & 11.6 \% & 14.7 \% & 0.8 \% & 18.4 * * * & 8.1 \% & 10.9 \% & 0.8 \% & 14.1 * * * \\ \mathbf{2 0 0 6} & 606 & 10.8 \% & 14.5 \% & 0.9 \% & 16.9 * * * & 7.4 \% & 10.9 \% & 0.8 \% & 13.0 * * * \\ \mathbf{2 0 0 7} & 397 & 2.8 \% & 4.9 \% & 0.9 \% & 5.8 * * * & -0.6 \% & 1.2 \% & 0.8 \% & 1.5 \\ \mathbf{2 0 0 8} & 174 & -9.1 \% & -12.0 \% & 1.2 \% & -10.1 * * * & -10.9 \% & -13.2 \% & 1.1 \% & -11.7 * * * \\ \mathbf{2 0 0 9} & 305 & -7.2 \% & -8.9 \% & 1.0 \% & -8.9 * * * & -0.3 \% & -2.5 \% & 1.0 \% & -2.4 * * *\end{array}$

Adjusted for Capital Gains Median Mean S.E. t-Stat 
Table 2B:

Equal-Weighted Percentage Difference in Sales Price and Appraised Value

\section{By Property Type}

This table presents statistics for the equally weighted percentage difference in sales price and appraised values two quarters prior to the sale date. Statistics are presented annually by date of appraisal on both an unadjusted and an adjusted basis, where the adjustment rolls back sales price by the percentage capital gain from time of the appraisal until the time of the next quarter. For each year, the table shows the mean and a t-statistic for the null hypothesis that the mean difference is zero, indicating that the appraisal is an unbiased estimate of the sales price. *,**, and *** indicate that the mean is statistically different from zero at the $0.10,0.05$ and 0.01 levels, respectively.

\begin{tabular}{|c|c|c|c|c|c|c|c|c|c|c|c|c|c|c|c|}
\hline \multirow[b]{2}{*}{ Year } & \multicolumn{3}{|c|}{ All Types } & \multicolumn{3}{|c|}{ Office } & \multicolumn{3}{|c|}{ Retail } & \multicolumn{3}{|c|}{ Apartment } & \multicolumn{3}{|c|}{ Industrial } \\
\hline & Obs. & Mean & t-Stat & Obs. & Mean & t-Stat & Obs. & Mean & t-Stat & Obs. & Mean & t-Stat & Obs. & Mean & t-Stat \\
\hline All & 7,214 & $3.5 \%$ & $14.0 * * *$ & 2,085 & $3.7 \%$ & $8.4 * * *$ & 1,220 & $4.9 \%$ & $5.7 * * *$ & 1,436 & $4.9 \%$ & $11.7 * * *$ & 2,473 & $1.9 \%$ & $4.7 * * *$ \\
\hline 1984 & 44 & $-6.4 \%$ & $-4.9 * * *$ & 19 & $-8.3 \%$ & $-6.0 * * *$ & 8 & $-4.9 \%$ & $-4.3 * * *$ & 1 & $9.9 \%$ & & 16 & $-5.8 \%$ & $-2.0 * *$ \\
\hline 1985 & 37 & $-1.0 \%$ & -0.6 & 8 & $5.0 \%$ & 1.1 & 5 & $-0.3 \%$ & -0.3 & 0 & & & 24 & $-3.1 \%$ & -1.5 \\
\hline 1986 & 120 & $-1.2 \%$ & -1.1 & 30 & $-4.8 \%$ & $-1.7 *$ & 26 & $-0.7 \%$ & -0.5 & 3 & $-6.2 \%$ & -2.3 & 61 & $0.6 \%$ & 0.4 \\
\hline 1987 & 93 & $-1.9 \%$ & -1.0 & 24 & $-3.3 \%$ & -0.6 & 21 & $0.7 \%$ & 0.2 & 1 & $-5.3 \%$ & & 47 & $-2.4 \%$ & -1.2 \\
\hline 1988 & 125 & $-6.1 \%$ & $-3.9 * * *$ & 28 & $-13.3 \%$ & $-3.8 * * *$ & 25 & $-4.6 \%$ & -1.2 & 8 & $-5.2 \%$ & $-1.7 *$ & 64 & $-3.7 \%$ & $-1.7 *$ \\
\hline 1989 & 121 & $-7.0 \%$ & $-4.9 * * *$ & 47 & $-9.1 \%$ & $-3.7 * * *$ & 12 & $-5.0 \%$ & $-1.9 *$ & 5 & $-6.2 \%$ & $-1.9 *$ & 57 & $-5.8 \%$ & $-2.7 * * *$ \\
\hline 1990 & 136 & $-9.5 \%$ & $-9.0 * * *$ & 45 & $-10.6 \%$ & $-4.5 * * *$ & 14 & $-0.4 \%$ & -0.3 & 6 & $-1.5 \%$ & -1.1 & 71 & $-11.3 \%$ & $-9.3 * * *$ \\
\hline 1991 & 69 & $-6.1 \%$ & $-4.2 * * *$ & 24 & $-3.5 \%$ & -1.2 & 6 & $-5.9 \%$ & $-2.0 * *$ & 4 & $-0.8 \%$ & -0.4 & 35 & $-8.6 \%$ & $-4.5 * * *$ \\
\hline 1992 & 111 & $-1.2 \%$ & -0.7 & 36 & $1.1 \%$ & 0.3 & 21 & $2.2 \%$ & 0.7 & 13 & $-10.8 \%$ & -1.6 & 41 & $-2.0 \%$ & -1.1 \\
\hline 1993 & 149 & $-1.4 \%$ & -1.0 & 45 & $0.9 \%$ & 0.3 & 20 & $-0.8 \%$ & -0.5 & 40 & $-1.8 \%$ & -0.7 & 44 & $-3.5 \%$ & $-1.7 *$ \\
\hline 1994 & 197 & $0.4 \%$ & 0.2 & 48 & $1.2 \%$ & 0.3 & 29 & $-5.9 \%$ & -1.4 & 37 & $5.0 \%$ & $3.7 * * *$ & 83 & $0.0 \%$ & 0.0 \\
\hline 1995 & 173 & $0.8 \%$ & 0.2 & 57 & $1.5 \%$ & 0.7 & 30 & $15.9 \%$ & 1.0 & 31 & $2.3 \%$ & 1.4 & 55 & $-8.8 \%$ & -1.3 \\
\hline 1996 & 393 & $3.2 \%$ & $3.1 * * *$ & 109 & $6.2 \%$ & $2.9 * * *$ & 73 & $1.4 \%$ & 0.4 & 71 & $0.7 \%$ & 0.5 & 140 & $2.9 \%$ & $2.4 * *$ \\
\hline 1997 & 403 & $8.1 \%$ & $4.5 * * *$ & 105 & $13.3 \%$ & $5.4 * * *$ & 117 & $6.6 \%$ & 1.2 & 65 & $5.9 \%$ & $5.1 * * *$ & 116 & $6.2 \%$ & $4.8 * * *$ \\
\hline 1998 & 409 & $4.4 \%$ & $6.2 * * *$ & 106 & $5.6 \%$ & $4.1 * * *$ & 118 & $3.9 \%$ & $2.4 * *$ & 69 & $6.2 \%$ & $4.7 * * *$ & 116 & $2.9 \%$ & $2.3 * *$ \\
\hline 1999 & 268 & $1.3 \%$ & $1.9 *$ & 91 & $0.5 \%$ & 0.5 & 53 & $3.6 \%$ & $1.8 *$ & 48 & $3.5 \%$ & $3.0 * * *$ & 76 & $-0.9 \%$ & -0.7 \\
\hline 2000 & 317 & $1.0 \%$ & 0.7 & 104 & $-0.3 \%$ & -0.2 & 55 & $-3.7 \%$ & $-1.8 *$ & 66 & $3.1 \%$ & $2.3 * *$ & 92 & $3.7 \%$ & 0.9 \\
\hline 2001 & 310 & $0.6 \%$ & 0.8 & 72 & $-1.8 \%$ & -1.2 & 50 & $-0.8 \%$ & -0.4 & 109 & $3.9 \%$ & $5.4 * * *$ & 79 & $-1.1 \%$ & -0.6 \\
\hline 2002 & 383 & $3.5 \%$ & $4.8 * * *$ & 89 & $1.8 \%$ & 1.2 & 80 & $7.9 \%$ & $4.1 * * *$ & 81 & $5.5 \%$ & $4.6 * * *$ & 133 & $0.8 \%$ & 0.7 \\
\hline 2003 & 456 & $4.3 \%$ & $5.5 * * *$ & 129 & $3.4 \%$ & $3.0 * * *$ & 83 & $5.7 \%$ & $2.4 * *$ & 106 & $3.9 \%$ & $3.4 * * *$ & 138 & $4.5 \%$ & $2.7 * * *$ \\
\hline 2004 & 717 & $10.1 \%$ & $14.8 * * *$ & 188 & $6.1 \%$ & $5.0 * * *$ & 170 & $14.8 \%$ & $10.0 * * *$ & 110 & $8.9 \%$ & $5.4 * * *$ & 249 & $10.4 \%$ & $8.9 * * *$ \\
\hline 2005 & 697 & $10.9 \%$ & $14.1 * * *$ & 220 & $12.6 \%$ & $8.4 * * *$ & 60 & $10.3 \%$ & $3.2 * * *$ & 163 & $12.8 \%$ & $7.9 * * *$ & 254 & $8.3 \%$ & $7.9 * * *$ \\
\hline 2006 & 606 & $10.9 \%$ & $13.0 * * *$ & 205 & $12.3 \%$ & $7.9 * * *$ & 50 & $5.9 \%$ & $2.5 * *$ & 148 & $12.7 \%$ & $7.8 * * *$ & 203 & $9.3 \%$ & $6.8 * * *$ \\
\hline 2007 & 397 & $1.2 \%$ & 1.5 & 134 & $3.8 \%$ & $2.6 * * *$ & 39 & $-0.5 \%$ & -0.3 & 107 & $1.4 \%$ & 0.8 & 117 & $-1.4 \%$ & -1.1 \\
\hline 2008 & 174 & $-13.2 \%$ & $-11.7 * * *$ & 46 & $-15.8 \%$ & $-6.3 * * *$ & 13 & $-11.6 \%$ & $-2.1 * *$ & 57 & $-10.5 \%$ & $-5.7 * * *$ & 58 & $-14.3 \%$ & $-8.4 * * *$ \\
\hline 2009 & 305 & $-2.5 \%$ & $-2.4 * *$ & 76 & $-3.8 \%$ & $-1.8 *$ & 40 & $5.2 \%$ & $2.3 * *$ & 87 & $1.0 \%$ & 0.6 & 102 & $-7.4 \%$ & $-3.9 * * *$ \\
\hline
\end{tabular}




\section{Table 3A:}

Value-Weighted Percentage Difference in Sales Price and Appraised Value

This table presents statistics for the value-weighted percentage difference in sales price and appraised values two quarters prior to the sale date. Statistics are presented annually by date of appraisal on both an unadjusted and an adjusted basis, where the adjustment rolls back sales price by the percentage capital gain from time of the appraisal until the time of the next quarter. For each year, the table shows the median, mean, and standard error, as well as a t-statistic for the null hypothesis that the mean difference is zero, indicating that the appraisal is an unbiased estimate of the sales price. $*, * *$, and $* * *$ indicate that the mean is statistically different from zero at the $0.10,0.05$ and 0.01 levels, respectively.

Unadjusted for Capital Gains

Year Obs. Median Mean S.E. t-Stat

$\begin{array}{rrrrrrrrrr}\text { Total } & 7,214 & 4.2 \% & 6.7 \% & 0.2 \% & 30.8 * * * & 2.9 \% & 5.0 \% & 0.2 \% & 24.0 * * * \\ & & & & & & & & & \\ \mathbf{1 9 8 4} & 44 & -1.4 \% & -1.7 \% & 1.0 \% & -1.8 * & -2.8 \% & -3.7 \% & 1.0 \% & -3.8 * * * \\ \mathbf{1 9 8 5} & 37 & 1.7 \% & 3.9 \% & 2.0 \% & 1.9 * & 0.3 \% & 2.2 \% & 2.0 \% & 1.1 \\ \mathbf{1 9 8 6} & 120 & 0.3 \% & 0.2 \% & 0.9 \% & 0.2 & -1.3 \% & -1.5 \% & 0.9 \% & -1.7 * \\ \mathbf{1 9 8 7} & 93 & 0.4 \% & 2.4 \% & 1.6 \% & 1.5 & -0.9 \% & 1.2 \% & 1.6 \% & 0.8 \\ \mathbf{1 9 8 8} & 125 & 0.0 \% & 0.0 \% & 1.4 \% & 0.0 & -2.1 \% & -1.5 \% & 1.4 \% & -1.1 \\ \mathbf{1 9 8 9} & 121 & 0.0 \% & -1.7 \% & 1.5 \% & -1.2 & -1.2 \% & -3.1 \% & 1.4 \% & -2.2 * * \\ \mathbf{1 9 9 0} & 136 & -2.9 \% & -10.1 \% & 1.8 \% & -5.7 * * * & -3.6 \% & -10.8 \% & 1.8 \% & -6.2 * * * \\ \mathbf{1 9 9 1} & 69 & -6.3 \% & -9.0 \% & 1.1 \% & -8.2 * * * & -5.3 \% & -7.8 \% & 1.1 \% & -7.0 * * * \\ \mathbf{1 9 9 2} & 111 & -1.9 \% & -4.3 \% & 1.5 \% & -3.0 * * * & 0.5 \% & -2.2 \% & 1.5 \% & -1.5 \\ \mathbf{1 9 9 3} & 149 & 0.0 \% & -2.8 \% & 1.3 \% & -2.2 * * & 0.7 \% & -2.0 \% & 1.3 \% & -1.5 \\ \mathbf{1 9 9 4} & 197 & 1.2 \% & -0.2 \% & 1.5 \% & -0.1 & 0.9 \% & -0.3 \% & 1.5 \% & -0.2 \\ \mathbf{1 9 9 5} & 173 & 0.0 \% & -0.6 \% & 1.5 \% & -0.4 & -0.6 \% & -1.2 \% & 1.4 \% & -0.9 \\ \mathbf{1 9 9 6} & 393 & 1.0 \% & 3.3 \% & 0.7 \% & 4.4 * * * & 0.3 \% & 2.3 \% & 0.7 \% & 3.2 * * * \\ \mathbf{1 9 9 7} & 403 & 4.4 \% & 8.4 \% & 0.8 \% & 10.7 * * * & 3.2 \% & 6.7 \% & 0.8 \% & 8.7 * * * \\ \mathbf{1 9 9 8} & 409 & 4.9 \% & 6.9 \% & 0.6 \% & 11.7 * * * & 1.8 \% & 3.8 \% & 0.6 \% & 6.6 * * * \\ \mathbf{1 9 9 9} & 268 & 1.1 \% & 2.2 \% & 0.5 \% & 4.0 * * * & -0.9 \% & 0.5 \% & 0.5 \% & 1.0 \\ \mathbf{2 0 0 0} & 317 & 2.8 \% & 3.8 \% & 0.8 \% & 4.6 * * * & 1.6 \% & 2.3 \% & 0.8 \% & 2.8 * * * \\ \mathbf{2 0 0 1} & 310 & -0.3 \% & 0.2 \% & 0.6 \% & 0.3 & -1.0 \% & -1.0 \% & 0.6 \% & -1.5 \\ \mathbf{2 0 0 2} & 383 & 1.5 \% & 3.7 \% & 0.8 \% & 4.8 * * * & 2.1 \% & 3.8 \% & 0.8 \% & 5.0 * * * \\ \mathbf{2 0 0 3} & 456 & 6.4 \% & 6.8 \% & 0.7 \% & 9.8 * * * & 5.9 \% & 6.3 \% & 0.7 \% & 9.1 * * * \\ \mathbf{2 0 0 4} & 717 & 11.0 \% & 11.8 \% & 0.6 \% & 18.9 * * * & 9.2 \% & 9.9 \% & 0.6 \% & 16.3 * * * \\ \mathbf{2 0 0 5} & 697 & 11.9 \% & 15.7 \% & 0.9 \% & 18.2 * * * & 8.7 \% & 11.8 \% & 0.8 \% & 14.2 * * * \\ \mathbf{2 0 0 6} & 606 & 15.1 \% & 16.9 \% & 0.8 \% & 21.2 * * * & 11.7 \% & 13.2 \% & 0.8 \% & 17.0 * * * \\ \mathbf{2 0 0 7} & 397 & 3.9 \% & 7.8 \% & 0.8 \% & 10.0 * * * & 0.3 \% & 4.0 \% & 0.7 \% & 5.3 * * * \\ \mathbf{2 0 0 8} & 174 & -12.8 \% & -16.0 \% & 1.3 \% & -12.3 * * * & -14.6 \% & -17.5 \% & 1.2 \% & -14.1 * * * \\ \mathbf{2 0 0 9} & 305 & -4.2 \% & -6.6 \% & 0.8 \% & -7.7 * * * & 2.2 \% & -0.3 \% & 0.9 \% & -0.4 \\ & & & & & & & & & \end{array}$

Adjusted for Capital Gains Median Mean S.E. t-Stat 
Table 3B:

Value-Weighted Percentage Difference in Sales Price and Appraised Value

This table presents statistics for the value-weighted percentage difference in sales price and appraised values two quarters prior to the sale date. Statistics are presented annually by date of appraisal on both an unadjusted and an adjusted basis, where the adjustment rolls back sales price by the percentage capital gain from time of the appraisal until the time of the next quarter. For each year, the table shows the median, mean, and standard error, as well as a t-statistic for the null hypothesis that the mean difference is zero, indicating that the appraisal is an unbiased estimate of the sales price. *, **, and *** indicate that the mean is statistically different from zero at the $0.10,0.05$ and 0.01 levels, respectively.

\begin{tabular}{|c|c|c|c|c|c|c|c|c|c|c|c|c|c|c|c|}
\hline \multirow[b]{2}{*}{ Year } & \multicolumn{3}{|c|}{ All Types } & \multicolumn{3}{|c|}{ Office } & \multicolumn{3}{|c|}{ Retail } & \multicolumn{3}{|c|}{ Apartment } & \multicolumn{3}{|c|}{ Industrial } \\
\hline & Obs. & Mean & t-Stat. & Obs. & Mean & t-Stat. & Obs. & Mean & t-Stat. & Obs. & Mean & t-Stat. & Obs. & Mean & t-Stat. \\
\hline All & 7,214 & $5.0 \%$ & 24.0 & 2,085 & $5.6 \%$ & 13.4 & 1,220 & $4.7 \%$ & 10.9 & 1,436 & $5.6 \%$ & 14.0 & 2,473 & $3.1 \%$ & 8.0 \\
\hline 1984 & 44 & $-3.7 \%$ & $-3.8 * * *$ & 19 & $-4.6 \%$ & $-3.4 * * *$ & 8 & $-2.6 \%$ & $-2.6 * * *$ & 1 & $9.9 \%$ & & 16 & $-4.9 \%$ & -1.6 \\
\hline 1985 & 37 & $2.2 \%$ & 1.1 & 8 & $12.1 \%$ & $2.3 * *$ & 5 & $-0.2 \%$ & -0.2 & & & & 24 & $-2.6 \%$ & -1.4 \\
\hline 1986 & 120 & $-1.5 \%$ & $-1.7 *$ & 30 & $-2.6 \%$ & -1.4 & 26 & $-1.3 \%$ & -1.0 & 3 & $-5.7 \%$ & $-2.0 * *$ & 61 & $1.1 \%$ & 0.8 \\
\hline 1987 & 93 & $1.2 \%$ & 0.8 & 24 & $-1.4 \%$ & -0.4 & 21 & $3.4 \%$ & 1.1 & 1 & $-5.3 \%$ & & 47 & $3.1 \%$ & 1.4 \\
\hline 1988 & 125 & $-1.5 \%$ & -1.1 & 28 & $-8.2 \%$ & $-3.7 * * *$ & 25 & $4.0 \%$ & 1.2 & 8 & $-5.3 \%$ & $-1.7 *$ & 64 & $-1.9 \%$ & -1.1 \\
\hline 1989 & 121 & $-3.1 \%$ & $-2.2 * *$ & 47 & $-6.8 \%$ & $-2.4 * *$ & 12 & $2.9 \%$ & 1.4 & 5 & $-6.6 \%$ & $-2.2 * *$ & 57 & $-2.0 \%$ & -1.0 \\
\hline 1990 & 136 & $-10.8 \%$ & $-6.2 * * *$ & 45 & $-16.1 \%$ & $-4.3 * * *$ & 14 & $-1.3 \%$ & -1.1 & 6 & $-1.8 \%$ & $-1.8 *$ & 71 & $-8.2 \%$ & $-6.2 * * *$ \\
\hline 1991 & 69 & $-7.8 \%$ & $-7.0 * * *$ & 24 & $-9.1 \%$ & $-5.2 * * *$ & 6 & $-4.3 \%$ & $-2.1 * *$ & 4 & $-0.6 \%$ & -0.4 & 35 & $-8.9 \%$ & $-4.1 * * *$ \\
\hline 1992 & 111 & $-2.2 \%$ & -1.5 & 36 & $3.2 \%$ & 0.7 & 21 & $-1.9 \%$ & -0.6 & 13 & $-6.9 \%$ & -1.5 & 41 & $-2.1 \%$ & -1.5 \\
\hline 1993 & 149 & $-2.0 \%$ & -1.5 & 45 & $0.2 \%$ & 0.1 & 20 & $1.2 \%$ & 1.2 & 40 & $-2.7 \%$ & -1.0 & 44 & $-7.9 \%$ & -3.3 \\
\hline 1994 & 197 & $-0.3 \%$ & -0.2 & 48 & $-3.4 \%$ & -0.8 & 29 & $-1.9 \%$ & -0.4 & 37 & $3.7 \%$ & $3.3 * * *$ & 83 & $1.6 \%$ & $1.0 * * *$ \\
\hline 1995 & 173 & $-1.2 \%$ & -0.9 & 57 & $0.1 \%$ & 0.0 & 30 & $-1.9 \%$ & -1.2 & 31 & $3.4 \%$ & $2.1 * *$ & 55 & $-7.6 \%$ & -1.4 \\
\hline 1996 & 393 & $2.3 \%$ & $3.2 * * *$ & 109 & $4.9 \%$ & $2.8 * * *$ & 73 & $-3.4 \%$ & $-2.6 * * *$ & 71 & $2.6 \%$ & $2.6 * * *$ & 140 & $3.4 \%$ & $3.4 * * *$ \\
\hline 1997 & 403 & $6.7 \%$ & $8.7 * * *$ & 105 & $10.6 \%$ & $5.5 * * *$ & 117 & $3.6 \%$ & $3.1 * * *$ & 65 & $6.9 \%$ & $5.6 * * *$ & 116 & $5.8 \%$ & $4.6 * * *$ \\
\hline 1998 & 409 & $3.8 \%$ & $6.6 * * *$ & 106 & $4.6 \%$ & $4.4 * * *$ & 118 & $2.7 \%$ & $2.3 * *$ & 69 & $4.4 \%$ & $3.6 * * *$ & 116 & $3.9 \%$ & $3.5 * * *$ \\
\hline 1999 & 268 & $0.5 \%$ & 1.0 & 91 & $0.3 \%$ & 0.4 & 53 & $0.9 \%$ & 0.7 & 48 & $3.9 \%$ & $3.3 * * *$ & 76 & $-2.0 \%$ & $-1.9 *$ \\
\hline 2000 & 317 & $2.3 \%$ & $2.8 * * *$ & 104 & $2.7 \%$ & $2.3 * *$ & 55 & $-1.7 \%$ & -1.2 & 66 & $4.7 \%$ & $3.5 * * *$ & 92 & $2.4 \%$ & 0.9 \\
\hline 2001 & 310 & $-1.0 \%$ & -1.5 & 72 & $-2.9 \%$ & $-2.1 * *$ & 50 & $-3.3 \%$ & $-3.0 * * *$ & 109 & $3.9 \%$ & $5.5 * * *$ & 79 & $-3.3 \%$ & $-1.8 *$ \\
\hline 2002 & 383 & $3.8 \%$ & $5.0 * * *$ & 89 & $-2.3 \%$ & -1.2 & 80 & $8.7 \%$ & $5.7 * * *$ & 81 & $5.3 \%$ & $4.5 * * *$ & 133 & $1.8 \%$ & $1.7 *$ \\
\hline 2003 & 456 & $6.3 \%$ & $9.1 * * *$ & 129 & $5.8 \%$ & $6.4 * * *$ & 83 & $10.5 \%$ & $6.1 * * *$ & 106 & $5.1 \%$ & $4.2 * * *$ & 138 & $3.1 \%$ & 1.6 \\
\hline 2004 & 717 & $9.9 \%$ & $16.3 * * *$ & 188 & $8.3 \%$ & $7.4 * * *$ & 170 & $12.4 \%$ & $11.0 * * *$ & 110 & $11.2 \%$ & $7.3 * * *$ & 249 & $10.1 \%$ & $8.1 * * *$ \\
\hline 2005 & 697 & $11.8 \%$ & $14.2 * * *$ & 220 & $14.9 \%$ & $10.4 * * *$ & 60 & $8.8 \%$ & $3.1 * * *$ & 163 & $11.9 \%$ & $7.9 * * *$ & 254 & $3.6 \%$ & $2.2 * *$ \\
\hline 2006 & 606 & $13.2 \%$ & $17.0 * * *$ & 205 & $15.8 \%$ & $11.2 * * *$ & 50 & $8.4 \%$ & $3.0 * * *$ & 148 & $9.6 \%$ & $7.1 * * *$ & 203 & $12.6 \%$ & $10.4 * * *$ \\
\hline 2007 & 397 & $4.0 \%$ & $5.3 * * *$ & 134 & $6.2 \%$ & $4.4 * * *$ & 39 & $1.7 \%$ & 0.7 & 107 & $2.0 \%$ & $1.8 *$ & 117 & $0.7 \%$ & $0.5 *$ \\
\hline 2008 & 174 & $-17.5 \%$ & $-14.1 * * *$ & 46 & $-21.6 \%$ & $-7.9 * * *$ & 13 & $-15.0 \%$ & $-4.3 * * *$ & 57 & $-12.0 \%$ & $-6.5 * * *$ & 58 & $-15.0 \%$ & $-10.2 * * *$ \\
\hline 2009 & 305 & $-0.3 \%$ & -0.4 & 76 & $0.0 \%$ & 0.0 & 40 & $5.9 \%$ & 2.6 & 87 & $2.2 \%$ & $1.7 *$ & 102 & $-11.2 \%$ & $-6.9 * * *$ \\
\hline
\end{tabular}




\section{Table 4A:}

Equally Weighted Absolute Percentage Difference in Sales Price and Appraised Value This table presents statistics for the equally weighted absolute percentage difference in sales price and appraised values two quarters prior to the sale date. Statistics are presented annually by date of appraisal on both an unadjusted and an adjusted basis, where the adjustment rolls back sales price by the percentage capital gain from time of the appraisal until the time of the next quarter. For each year, the table shows the median, mean, and standard error, as well as a t-statistic for the null hypothesis that the mean difference is zero, indicating that the appraisal is an unbiased estimate of the sales price. $*, * *$, and $* * *$ indicate that the mean is statistically different from zero at the $0.10,0.05$ and 0.01 levels, respectively.

\section{Unadjusted for Capital Gains}

Year Obs. Median Mean S.E. t-Stat

\begin{tabular}{|c|c|c|c|c|c|c|c|c|c|}
\hline \multirow{3}{*}{$\begin{array}{l}\text { Year } \\
\text { Total }\end{array}$} & \multirow{3}{*}{$\begin{array}{r}\text { Obs. } \\
7,214\end{array}$} & \multicolumn{4}{|c|}{ Unadjusted for Capital Gains } & \multicolumn{4}{|c|}{ Adjusted for Capital Gains } \\
\hline & & Median & Mean & S.E. & $-S t$ & Median & Mean & SF & t-Stat \\
\hline & & $8.5 \%$ & $13.2 \%$ & $0.2 \%$ & $62.0 * * *$ & $8.0 \%$ & $12.4 \%$ & $0.2 \%$ & $60.7 * *$ \\
\hline 1984 & 44 & $6.8 \%$ & $7.3 \%$ & $0.9 \%$ & $7.8 * * *$ & $8.9 \%$ & $8.8 \%$ & $0.9 \%$ & $9.8 * * *$ \\
\hline 1985 & 37 & $5.2 \%$ & $6.9 \%$ & $1.2 \%$ & $5.8 * * *$ & $4.2 \%$ & $6.9 \%$ & $1.2 \%$ & $5.5 * * *$ \\
\hline 1986 & 120 & $5.3 \%$ & $8.1 \%$ & $0.8 \%$ & $10.1 * * *$ & $5.6 \%$ & $8.2 \%$ & $0.8 \%$ & $10.4 * * *$ \\
\hline 1987 & 93 & $8.2 \%$ & $11.6 \%$ & $1.4 \%$ & $8.0 * * *$ & $7.7 \%$ & $11.7 \%$ & $1.4 \%$ & $8.4 * * *$ \\
\hline 1988 & 125 & $9.5 \%$ & $12.8 \%$ & $1.2 \%$ & $10.6 * * *$ & $10.0 \%$ & $13.0 \%$ & $1.2 \%$ & $10.7 * * *$ \\
\hline 1989 & 121 & $8.0 \%$ & $11.7 \%$ & $1.1 \%$ & $10.3 * * *$ & $9.0 \%$ & & $1.1 \%$ & $10.6^{* * *}$ \\
\hline 1990 & 136 & $8.7 \%$ & $11.0 \%$ & $0.9 \%$ & $11.9 * * *$ & $\%$ & & $0.9 \%$ & $12.3 * * * *$ \\
\hline 1991 & 69 & $6.4 \%$ & & $1.2 \%$ & $7.7 * * *$ & 5 & & & $7.5 * * *$ \\
\hline 1992 & 111 & $6.8 \%$ & $11.4 \%$ & & $* * *$ & $\%$ & & 1 & $3 * * *$ \\
\hline 1993 & 149 & $5.8 \%$ & $9.7 \%$ & $1.0 \%$ & $6 * * *$ & $\%$ & $\%$ & 1. & $9.8 * * *$ \\
\hline 1994 & 197 & $6.0 \%$ & $11.6 \%$ & $1.2^{c}$ & $5 * * *$ & $\%$ & 11 & 1.2 & $9.6 * * *$ \\
\hline 1995 & 173 & $5.7 \%$ & $13.5 \%$ & $3.4 \%$ & $9 * * *$ & $\%$ & $13.4 \%$ & $3.4 \%$ & $3.9 * * *$ \\
\hline 1996 & 393 & $6.2 \%$ & $10.6 \%$ & $0.9 \%$ & $11.7 * * *$ & $\%$ & $10.5 \%$ & $0.9 \%$ & $11.7 * * *$ \\
\hline 1997 & 403 & $8.0 \%$ & $14.0 \%$ & $1.8 \%$ & $9 * * *$ & $7.5 \%$ & $13.2 \%$ & $1.7 \%$ & $7.6 * * *$ \\
\hline 1998 & 409 & $8.0 \%$ & $12.0 \%$ & $0.6 \%$ & $20.5 * * *$ & $6.7 \%$ & $10.6 \%$ & $0.5 \%$ & $19.8 * * *$ \\
\hline 1999 & 268 & $5.6 \%$ & $7.9 \%$ & $0.5 \%$ & $15.8 * * *$ & $5.3 \%$ & $7.7 \%$ & $0.5 \%$ & $16.3^{* * *}$ \\
\hline 2000 & 317 & $5.7 \%$ & $9.5 \%$ & $1.3 \%$ & $7.5 * * *$ & $5.6 \%$ & $9.4 \%$ & $1.2 \%$ & $7.6 * * *$ \\
\hline 2001 & 310 & $5.3 \%$ & $8.4 \%$ & $0.6 \%$ & $14.8 * * *$ & $5.3 \%$ & $8.3 \%$ & $0.6 \%$ & $14.8 * * *$ \\
\hline 2002 & 383 & $7.4 \%$ & $10.3 \%$ & $0.5 \%$ & $19.0 * * *$ & $7.5 \%$ & $10.3 \%$ & $0.5 \%$ & $19.0 * * *$ \\
\hline 2003 & 456 & $8.2 \%$ & $11.8 \%$ & $0.6 \%$ & $20.0 * * *$ & $8.0 \%$ & $11.7 \%$ & $0.6 \%$ & $19.8 * * *$ \\
\hline 2004 & 717 & $14.0 \%$ & $17.2 \%$ & $0.5 \%$ & $32.9 * * *$ & $13.2 \%$ & $16.0 \%$ & $0.5 \%$ & $32.1 * * *$ \\
\hline 2005 & 697 & $14.1 \%$ & $18.6 \%$ & $0.7 \%$ & $27.6 * * *$ & $11.0 \%$ & $16.2 \%$ & $0.6 \%$ & $26.0 * * *$ \\
\hline 2006 & 606 & 6 & & $0.7 \%$ & $24.8 * * *$ & $11.1 \%$ & & $0.7 \%$ & $23.5 * * *$ \\
\hline 2007 & 397 & & & & $17.9 * * *$ & & & $0.6 \%$ & $18.1 * * *$ \\
\hline 2008 & 174 & & & & $15.8 * * *$ & $9 \%$ & $7 \%$ & $0.9 \%$ & $16.7 * * * *$ \\
\hline 2009 & 305 & $11.9 \%$ & $14.8 \%$ & $0.7 \%$ & $19.8 * * *$ & $10.2 \%$ & $13.4 \%$ & $0.7 \%$ & $18.7 * *$ \\
\hline
\end{tabular}

\section{Adjusted for Capital Gains}

\begin{tabular}{|c|c|c|c|c|c|c|c|c|c|}
\hline \multirow{3}{*}{$\begin{array}{l}\text { Year } \\
\text { Total }\end{array}$} & \multirow{3}{*}{$\begin{array}{r}\text { Obs. } \\
7,214\end{array}$} & \multicolumn{4}{|c|}{ Unadjusted for Capital Gains } & \multicolumn{4}{|c|}{ Adjusted for Capital Gains } \\
\hline & & Median & Mean & S.E. & -Stat & Median & Mean & S.E. & t-Stat \\
\hline & & $8.5 \%$ & $13.2 \%$ & $0.2 \%$ & $62.0 * * *$ & $8.0 \%$ & $12.4 \%$ & $0.2 \%$ & $60.7 *$ \\
\hline 1984 & 44 & $6.8 \%$ & $7.3 \%$ & $0.9 \%$ & $7.8 * * *$ & $8.9 \%$ & $8.8 \%$ & $0.9 \%$ & $9.8 * * *$ \\
\hline 1985 & 37 & $5.2 \%$ & $6.9 \%$ & $1.2 \%$ & $5.8 * * *$ & $4.2 \%$ & $6.9 \%$ & $1.2 \%$ & $5.5 * * *$ \\
\hline 1986 & 120 & $5.3 \%$ & $8.1 \%$ & $0.8 \%$ & $10.1 * * *$ & $5.6 \%$ & $8.2 \%$ & $0.8 \%$ & $10.4 * * *$ \\
\hline 1987 & 93 & $8.2 \%$ & $11.6 \%$ & $1.4 \%$ & $8.0 * * *$ & $7.7 \%$ & $11.7 \%$ & $1.4 \%$ & $8.4 * * *$ \\
\hline 1988 & 125 & $9.5 \%$ & $12.8 \%$ & $1.2 \%$ & $10.6 * * *$ & $10.0 \%$ & $13.0 \%$ & $1.2 \%$ & $10.7 * * *$ \\
\hline 1989 & 121 & $8.0 \%$ & $11.7 \%$ & $1.1 \%$ & $10.3 * * *$ & $9.0 \%$ & & $1.1 \%$ & $10.6 * * *$ \\
\hline 1990 & 136 & $8.7 \%$ & $11.0 \%$ & $0.9 \%$ & $11.9 * * *$ & $\%$ & & $0.9 \%$ & $12.3 * * * *$ \\
\hline 1991 & 69 & $6.4 \%$ & & 1 & $7.7 * * *$ & $\%$ & & $1.2 \%$ & $.5 * * *$ \\
\hline 1992 & 111 & $6.8 \%$ & $11.4 \%$ & & $* * *$ & $\%$ & & 1. & $3 * * *$ \\
\hline 1993 & 149 & $5.8 \%$ & $9.7 \%$ & $1.0 \%$ & $6 * * *$ & $\%$ & $\%$ & $1.0 \%$ & $9.8 * * *$ \\
\hline 1994 & 197 & $6.0 \%$ & $11.6 \%$ & $1.2 \%$ & $5 * * *$ & 5 & $11.6 \%$ & $1.2 \%$ & $9.6 * * *$ \\
\hline 1995 & 173 & $5.7 \%$ & $13.5 \%$ & $3.4 \%$ & $9 * * *$ & 5 & 13 & $3.4 \%$ & $3.9 * * *$ \\
\hline 1996 & 393 & $6.2 \%$ & $10.6 \%$ & $0.9 \%$ & $11.7 * * *$ & $\%$ & $10.5 \%$ & $0.9 \%$ & $11.7 * * *$ \\
\hline 1997 & 403 & $8.0 \%$ & $14.0 \%$ & $1.8 \%$ & $9 * * *$ & $7.5 \%$ & $13.2 \%$ & $1.7 \%$ & $7.6 * * *$ \\
\hline 1998 & 409 & $8.0 \%$ & $12.0 \%$ & $0.6 \%$ & $20.5 * * *$ & $6.7 \%$ & $10.6 \%$ & $0.5 \%$ & $19.8 * * *$ \\
\hline 1999 & 268 & $5.6 \%$ & $7.9 \%$ & $0.5 \%$ & $15.8 * * *$ & $5.3 \%$ & $7.7 \%$ & $0.5 \%$ & $16.3^{* * *}$ \\
\hline 2000 & 317 & $5.7 \%$ & $9.5 \%$ & $1.3 \%$ & $7.5 * * *$ & $5.6 \%$ & $9.4 \%$ & $1.2 \%$ & $7.6 * * *$ \\
\hline 2001 & 310 & $5.3 \%$ & $8.4 \%$ & $0.6 \%$ & $14.8 * * *$ & $5.3 \%$ & $8.3 \%$ & $0.6 \%$ & $14.8 * * *$ \\
\hline 2002 & 383 & $7.4 \%$ & $10.3 \%$ & $0.5 \%$ & $19.0 * * *$ & $7.5 \%$ & $10.3 \%$ & $0.5 \%$ & $19.0 * * *$ \\
\hline 2003 & 456 & $8.2 \%$ & $11.8 \%$ & $0.6 \%$ & $20.0 * * *$ & $8.0 \%$ & $11.7 \%$ & $0.6 \%$ & $19.8 * * *$ \\
\hline 2004 & 717 & $14.0 \%$ & $17.2 \%$ & $0.5 \%$ & $32.9 * * *$ & $13.2 \%$ & $16.0 \%$ & $0.5 \%$ & $32.1 * * *$ \\
\hline 2005 & 697 & $14.1 \%$ & $18.6 \%$ & $0.7 \%$ & $27.6 * * *$ & $11.0 \%$ & $16.2 \%$ & $0.6 \%$ & $26.0 * * *$ \\
\hline 2006 & 606 & 13 & $18.2 \%$ & $0.7 \%$ & $24.8 * * *$ & $11.1 \%$ & & $0.7 \%$ & $23.5 *$ \\
\hline 2007 & 397 & & & & $17.9 * * *$ & & & $0.6 \%$ & $18.1 * *$ \\
\hline 2008 & 174 & & & & $15.8 * * *$ & $9 \%$ & $15.7 \%$ & $0.9 \%$ & $16.7 * * * *$ \\
\hline 2009 & 305 & $11.9 \%$ & $14.8 \%$ & $0.7 \%$ & $19.8 * * *$ & $10.2 \%$ & $13.4 \%$ & $0.7 \%$ & $18.7 * *$ \\
\hline
\end{tabular}




\section{Table 4B:}

\section{Equally Weighted Absolute Percentage Difference in Sales Price and Appraised Value}

\section{By Property Type}

This table presents statistics for the equally weighted absolute percentage difference in sales price and appraised values two quarters prior to the sale date. Statistics are presented annually by date of appraisal on an adjusted basis, where the adjustment rolls back sales price by the percentage capital gain from time of the appraisal until the time of the next quarter. For each year, the table shows the median and mean.

\begin{tabular}{|c|c|c|c|c|c|c|c|c|c|c|c|c|c|c|c|}
\hline & \multicolumn{3}{|c|}{ All Types } & \multicolumn{3}{|c|}{ Office } & \multicolumn{3}{|c|}{ Retail } & \multicolumn{3}{|c|}{ Apartment } & \multicolumn{3}{|c|}{ Industrial } \\
\hline Year & Obs. & Median & Mean & Obs. & Median & Mean & Obs. & Median & Mean & Obs. & Median & Mean & Obs. & Median & Mean \\
\hline All & 7,214 & $8.0 \%$ & $12.4 \%$ & 2,085 & $8.7 \%$ & $13.4 \%$ & 1,220 & $7.6 \%$ & $13.2 \%$ & 1,436 & $6.8 \%$ & $10.9 \%$ & 2,473 & $8.4 \%$ & $12.1 \%$ \\
\hline 1984 & 44 & $8.9 \%$ & $8.8 \%$ & 19 & $8.9 \%$ & $8.5 \%$ & 8 & $4.7 \%$ & $4.9 \%$ & 1 & $9.9 \%$ & $9.9 \%$ & 16 & $8.9 \%$ & $10.9 \%$ \\
\hline 1985 & 37 & $4.2 \%$ & $6.9 \%$ & 8 & $8.2 \%$ & $9.1 \%$ & 5 & $0.9 \%$ & $1.7 \%$ & & & & 24 & $5.6 \%$ & $7.2 \%$ \\
\hline 1986 & 120 & $5.6 \%$ & $8.2 \%$ & 30 & $7.0 \%$ & $10.8 \%$ & 26 & $3.6 \%$ & $5.2 \%$ & 3 & $8.6 \%$ & $6.2 \%$ & 61 & $6.1 \%$ & $8.2 \%$ \\
\hline 1987 & 93 & $7.7 \%$ & $11.7 \%$ & 24 & $9.5 \%$ & $16.4 \%$ & 21 & $6.1 \%$ & $10.1 \%$ & 1 & $5.3 \%$ & $5.3 \%$ & 47 & $8.0 \%$ & $10.2 \%$ \\
\hline 1988 & 125 & $10.0 \%$ & $13.0 \%$ & 28 & $11.0 \%$ & $15.3 \%$ & 25 & $6.0 \%$ & $12.1 \%$ & 8 & $8.9 \%$ & $8.7 \%$ & 64 & $10.6 \%$ & $12.9 \%$ \\
\hline 1989 & 121 & $9.0 \%$ & $11.9 \%$ & 47 & $12.0 \%$ & $14.2 \%$ & 12 & $7.8 \%$ & $8.0 \%$ & 5 & $4.9 \%$ & $6.3 \%$ & 57 & $8.8 \%$ & $11.4 \%$ \\
\hline 1990 & 136 & $8.8 \%$ & $11.3 \%$ & 45 & $10.0 \%$ & $13.0 \%$ & 14 & $1.9 \%$ & $3.3 \%$ & 6 & $1.9 \%$ & $2.6 \%$ & 71 & $15.2 \%$ & $12.6 \%$ \\
\hline 1991 & 69 & $5.6 \%$ & $9.1 \%$ & 24 & $5.9 \%$ & $9.5 \%$ & 6 & $4.3 \%$ & $6.3 \%$ & 4 & $2.8 \%$ & $3.0 \%$ & 35 & $7.1 \%$ & $10.1 \%$ \\
\hline 1992 & 111 & $6.7 \%$ & $11.7 \%$ & 36 & $13.0 \%$ & $16.4 \%$ & 21 & $6.8 \%$ & $10.0 \%$ & 13 & $4.9 \%$ & $14.6 \%$ & 41 & $4.9 \%$ & $7.6 \%$ \\
\hline 1993 & 149 & $5.5 \%$ & $10.0 \%$ & 45 & $5.6 \%$ & $11.7 \%$ & 20 & $3.1 \%$ & $4.6 \%$ & 40 & $5.5 \%$ & $10.9 \%$ & 44 & $7.5 \%$ & $9.7 \%$ \\
\hline 1994 & 197 & $5.9 \%$ & $11.6 \%$ & 48 & $10.1 \%$ & $18.1 \%$ & 29 & $4.6 \%$ & $12.1 \%$ & 37 & $4.3 \%$ & $6.3 \%$ & 83 & $5.9 \%$ & $10.1 \%$ \\
\hline 1995 & 173 & $5.4 \%$ & $13.4 \%$ & 57 & $5.5 \%$ & $10.9 \%$ & 30 & $8.3 \%$ & $24.6 \%$ & 31 & $5.0 \%$ & $7.0 \%$ & 55 & $4.3 \%$ & $13.6 \%$ \\
\hline 1996 & 393 & $6.0 \%$ & $10.5 \%$ & 109 & $6.0 \%$ & $12.0 \%$ & 73 & $6.5 \%$ & $12.9 \%$ & 71 & $4.6 \%$ & $7.1 \%$ & 140 & $6.7 \%$ & $9.9 \%$ \\
\hline 1997 & 403 & $7.5 \%$ & $13.2 \%$ & 105 & $10.2 \%$ & $16.9 \%$ & 117 & $6.6 \%$ & $15.5 \%$ & 65 & $4.1 \%$ & $7.4 \%$ & 116 & $7.4 \%$ & $10.8 \%$ \\
\hline 1998 & 409 & $6.7 \%$ & $10.6 \%$ & 106 & $6.5 \%$ & $10.7 \%$ & 118 & $7.2 \%$ & $12.4 \%$ & 69 & $7.0 \%$ & $9.4 \%$ & 116 & $6.1 \%$ & $9.6 \%$ \\
\hline 1999 & 268 & $5.3 \%$ & $7.7 \%$ & 91 & $5.6 \%$ & $7.2 \%$ & 53 & $8.4 \%$ & $10.3 \%$ & 48 & $4.4 \%$ & $6.2 \%$ & 76 & $5.1 \%$ & $7.5 \%$ \\
\hline 2000 & 317 & $5.6 \%$ & $9.4 \%$ & 104 & $5.6 \%$ & $9.0 \%$ & 55 & $6.9 \%$ & $9.8 \%$ & 66 & $7.5 \%$ & $8.8 \%$ & 92 & $4.3 \%$ & $10.3 \%$ \\
\hline 2001 & 310 & $5.3 \%$ & $8.3 \%$ & 72 & $6.1 \%$ & $9.0 \%$ & 50 & $3.9 \%$ & $8.7 \%$ & 109 & $4.8 \%$ & $6.5 \%$ & 79 & $5.8 \%$ & $9.8 \%$ \\
\hline 2002 & 383 & $7.5 \%$ & $10.3 \%$ & 89 & $6.3 \%$ & $9.0 \%$ & 80 & $8.5 \%$ & $13.3 \%$ & 81 & $7.7 \%$ & $9.1 \%$ & 133 & $7.5 \%$ & $10.2 \%$ \\
\hline 2003 & 456 & $8.0 \%$ & $11.7 \%$ & 129 & $7.6 \%$ & $10.3 \%$ & 83 & $10.0 \%$ & $15.2 \%$ & 106 & $6.4 \%$ & $9.1 \%$ & 138 & $8.7 \%$ & $12.7 \%$ \\
\hline 2004 & 717 & $13.2 \%$ & $16.0 \%$ & 188 & $9.9 \%$ & $13.3 \%$ & 170 & $17.1 \%$ & $19.4 \%$ & 110 & $7.6 \%$ & $13.3 \%$ & 249 & $15.6 \%$ & $17.0 \%$ \\
\hline 2005 & 697 & $11.0 \%$ & $16.2 \%$ & 220 & $13.7 \%$ & $18.9 \%$ & 60 & $7.0 \%$ & $15.3 \%$ & 163 & $8.8 \%$ & $16.2 \%$ & 254 & $11.3 \%$ & $14.1 \%$ \\
\hline 2006 & 606 & $11.1 \%$ & $16.1 \%$ & 205 & $11.7 \%$ & $17.8 \%$ & 50 & $7.8 \%$ & $11.7 \%$ & 148 & $10.9 \%$ & $16.2 \%$ & 203 & $11.7 \%$ & $15.2 \%$ \\
\hline 2007 & 397 & $7.0 \%$ & $11.0 \%$ & 134 & $9.1 \%$ & $12.5 \%$ & 39 & $4.3 \%$ & $7.3 \%$ & 107 & $6.7 \%$ & $11.4 \%$ & 117 & $6.7 \%$ & $10.3 \%$ \\
\hline 2008 & 174 & $11.9 \%$ & $15.7 \%$ & 46 & $13.3 \%$ & $17.5 \%$ & 13 & $11.3 \%$ & $17.5 \%$ & 57 & $10.9 \%$ & $13.9 \%$ & 58 & $11.9 \%$ & $15.5 \%$ \\
\hline 2009 & 305 & $10.2 \%$ & $13.4 \%$ & 76 & $13.1 \%$ & $15.4 \%$ & 40 & $11.6 \%$ & $12.3 \%$ & 87 & $8.1 \%$ & $11.0 \%$ & 102 & $10.5 \%$ & $14.4 \%$ \\
\hline
\end{tabular}




\section{Table 5A:}

Value-Weighted Absolute Percentage Difference in Sales Price and Appraised Value This table presents statistics for the equally weighted absolute percentage difference in sales price and appraised values two quarters prior to the sale date. Statistics are presented annually by date of appraisal on both an unadjusted and an adjusted basis, where the adjustment rolls back sales price by the percentage capital gain from time of the appraisal until the time of the next quarter. For each year, the table shows the median, mean, and standard error, as well as a t-statistic for the null hypothesis that the mean difference is zero, indicating that the appraisal is an unbiased estimate of the sales price. $*$, **, and $* * *$ indicate that the mean is statistically different from zero at the $0.10,0.05$ and 0.01 levels, respectively.

\section{Unadjusted for Capital Gains}

Year Obs. Median Mean S.E. t-Stat

$\begin{array}{rrrrrr}\text { Total } & 7,214 & 8.6 \% & 13.3 \% & 0.2 \% & 77.3 * * * \\ & & & & & \\ \mathbf{1 9 8 4} & 44 & 4.1 \% & 4.5 \% & 0.7 \% & 6.2 * * * \\ \mathbf{1 9 8 5} & 37 & 4.4 \% & 8.0 \% & 1.6 \% & 4.9 * * * \\ \mathbf{1 9 8 6} & 120 & 4.7 \% & 7.1 \% & 0.6 \% & 11.2 * * * \\ \mathbf{1 9 8 7} & 93 & 9.5 \% & 10.5 \% & 1.2 \% & 9.0 * * * \\ \mathbf{1 9 8 8} & 125 & 7.2 \% & 10.6 \% & 1.0 \% & 10.8 * * * \\ \mathbf{1 9 8 9} & 121 & 5.3 \% & 9.9 \% & 1.2 \% & 8.5 * * * \\ \mathbf{1 9 9 0} & 136 & 3.8 \% & 12.4 \% & 1.7 \% & 7.5 * * * \\ \mathbf{1 9 9 1} & 69 & 6.3 \% & 9.3 \% & 1.1 \% & 8.8 * * * \\ \mathbf{1 9 9 2} & 111 & 6.0 \% & 10.0 \% & 1.2 \% & 8.5 * * * \\ \mathbf{1 9 9 3} & 149 & 4.3 \% & 8.6 \% & 1.1 \% & 7.9 * * * \\ \mathbf{1 9 9 4} & 197 & 4.6 \% & 10.8 \% & 1.3 \% & 8.4 * * * \\ \mathbf{1 9 9 5} & 173 & 3.8 \% & 7.9 \% & 1.3 \% & 5.9 * * * \\ \mathbf{1 9 9 6} & 393 & 4.2 \% & 8.1 \% & 0.6 \% & 12.6 * * * \\ \mathbf{1 9 9 7} & 403 & 6.8 \% & 10.9 \% & 0.7 \% & 15.7 * * * \\ \mathbf{1 9 9 8} & 409 & 7.0 \% & 9.8 \% & 0.5 \% & 20.4 * * * \\ \mathbf{1 9 9 9} & 268 & 4.2 \% & 6.4 \% & 0.4 \% & 15.9 * * * \\ \mathbf{2 0 0 0} & 317 & 5.0 \% & 8.6 \% & 0.7 \% & 12.0 * * * \\ \mathbf{2 0 0 1} & 310 & 4.2 \% & 6.9 \% & 0.5 \% & 14.3 * * * \\ \mathbf{2 0 0 2} & 383 & 6.5 \% & 9.9 \% & 0.6 \% & 16.2 * * * \\ \mathbf{2 0 0 3} & 456 & 8.3 \% & 11.5 \% & 0.5 \% & 21.2 * * * \\ \mathbf{2 0 0 4} & 717 & 12.8 \% & 15.8 \% & 0.5 \% & 32.9 * * * \\ \mathbf{2 0 0 5} & 697 & 14.4 \% & 19.9 \% & 0.7 \% & 27.2 * * * \\ \mathbf{2 0 0 6} & 606 & 16.1 \% & 19.3 \% & 0.7 \% & 27.6 * * * * \\ \mathbf{2 0 0 7} & 397 & 8.9 \% & 12.0 \% & 0.6 \% & 19.3 * * * \\ \mathbf{2 0 0 8} & 174 & 13.0 \% & 17.8 \% & 1.2 \% & 15.3 * * * \\ \mathbf{2 0 0 9} & 305 & 10.2 \% & 12.2 \% & 0.6 \% & 19.9 * * * \\ & & & & & \end{array}$

\section{Adjusted for Capital Gains} Median Mean S.E. t-Stat

$\begin{array}{rrrr}7.7 \% & 12.3 \% & 0.2 \% & 76.6 * * * \\ & & & \\ 3.7 \% & 5.2 \% & 0.8 \% & 6.8 * * * \\ 3.0 \% & 7.7 \% & 1.6 \% & 4.7 * * * \\ 5.4 \% & 7.3 \% & 0.6 \% & 11.7 * * * \\ 9.1 \% & 10.5 \% & 1.1 \% & 9.4 * * * \\ 7.5 \% & 10.7 \% & 1.0 \% & 11.1 * * * \\ 6.0 \% & 9.9 \% & 1.2 \% & 8.6 * * * \\ 4.2 \% & 12.8 \% & 1.6 \% & 7.8 * * * \\ 5.4 \% & 8.8 \% & 1.0 \% & 8.7 * * * \\ 6.4 \% & 10.4 \% & 1.2 \% & 8.9 * * * \\ 4.8 \% & 8.9 \% & 1.1 \% & 8.3 * * * \\ 4.6 \% & 10.7 \% & 1.3 \% & 8.4 * * * \\ 4.4 \% & 7.9 \% & 1.3 \% & 6.0 * * * \\ 4.6 \% & 7.9 \% & 0.6 \% & 12.7 * * * \\ 6.6 \% & 10.2 \% & 0.7 \% & 15.4 * * * \\ 5.8 \% & 8.6 \% & 0.4 \% & 20.1 * * * \\ 4.1 \% & 6.3 \% & 0.4 \% & 17.1 * * * \\ 5.0 \% & 8.3 \% & 0.7 \% & 12.0 * * * \\ 4.5 \% & 7.2 \% & 0.5 \% & 15.1 * * * \\ 6.2 \% & 9.9 \% & 0.6 \% & 16.2 * * * \\ 7.9 \% & 11.2 \% & 0.5 \% & 20.8 * * * \\ 12.4 \% & 14.6 \% & 0.5 \% & 32.2 * * * \\ 11.5 \% & 17.4 \% & 0.7 \% & 25.6 * * * \\ 13.1 \% & 16.7 \% & 0.7 \% & 25.7 * * * \\ 7.6 \% & 10.9 \% & 0.5 \% & 20.0 * * * \\ 14.6 \% & 18.6 \% & 1.1 \% & 16.2 * * * \\ 8.7 \% & 11.5 \% & 0.6 \% & 21.0 * * * \\ & & & \end{array}$


Table 5B:

Value-Weighted Absolute Percentage Difference in Sales Price and Appraised Value

\section{By Property Type}

This table presents statistics for the value-weighted absolute percentage difference in sales price and appraised values two quarters prior to the sale date. Statistics are presented annually by date of appraisal on an adjusted basis, where the adjustment rolls back sales price by the percentage capital gain from time of the appraisal until the time of the next quarter. For each year, the table shows the median and mean.

\section{All Types $\quad$ Office $\quad$ Retail Apartment Industrial}

Obs. Median Mean Obs. Median Mean Obs. Median Mean Obs. Median Mean Obs. Median Mean

\begin{tabular}{|c|c|c|c|c|c|c|c|c|c|c|c|c|c|c|c|}
\hline & Obs. & Median & Mean & JDS. & Median & Ilean & UDS. & Median & viean & JDS. & Median & Mean & JDS. & Median & Vlean \\
\hline All & 7,214 & $7.7 \%$ & $12.3 \%$ & 2,085 & $8.7 \%$ & $13.8 \%$ & 1,220 & $6.1 \%$ & $10.3 \%$ & 1,436 & $7.1 \%$ & $10.9 \%$ & 2,473 & $8.8 \%$ & $12.8 \%$ \\
\hline 1984 & 44 & $3.7 \%$ & $5.2 \%$ & 19 & $4.2 \%$ & $5.8 \%$ & 8 & $1.4 \%$ & $2.6 \%$ & 1 & $9.9 \%$ & $9.9 \%$ & 16 & $8.7 \%$ & $10.3 \%$ \\
\hline 1985 & 37 & $3.0 \%$ & $7.7 \%$ & 8 & $8.9 \%$ & $14.0 \%$ & 5 & $0.8 \%$ & $1.6 \%$ & 0 & & & 24 & $2.4 \%$ & $5.9 \%$ \\
\hline 1986 & 120 & $5.4 \%$ & $7.3 \%$ & 30 & $6.5 \%$ & $8.3 \%$ & 26 & $3.5 \%$ & $5.4 \%$ & 3 & $8.6 \%$ & $5.7 \%$ & 61 & $3.7 \%$ & $6.9 \%$ \\
\hline 1987 & 93 & $9.1 \%$ & $10.5 \%$ & 24 & $11.0 \%$ & $11.5 \%$ & 21 & $4.1 \%$ & $8.9 \%$ & 1 & $5.3 \%$ & $5.3 \%$ & 47 & $6.2 \%$ & $11.1 \%$ \\
\hline 1988 & 125 & $7.5 \%$ & $10.7 \%$ & 28 & $10.1 \%$ & $10.1 \%$ & 25 & $4.5 \%$ & $10.9 \%$ & 8 & $8.9 \%$ & $9.0 \%$ & 64 & $11.2 \%$ & $11.5 \%$ \\
\hline 1989 & 121 & $6.0 \%$ & $9.9 \%$ & 47 & $5.6 \%$ & $13.0 \%$ & 12 & $6.0 \%$ & $5.5 \%$ & 5 & $6.1 \%$ & $6.7 \%$ & 57 & $6.6 \%$ & $9.4 \%$ \\
\hline 1990 & 136 & $4.2 \%$ & $12.8 \%$ & 45 & $10.4 \%$ & $18.5 \%$ & 14 & $1.7 \%$ & $2.5 \%$ & 6 & $1.7 \%$ & $2.4 \%$ & 71 & $6.7 \%$ & $10.5 \%$ \\
\hline 1991 & 69 & $5.4 \%$ & $8.8 \%$ & 24 & $13.4 \%$ & $10.0 \%$ & 6 & $5.3 \%$ & $4.5 \%$ & 4 & $2.3 \%$ & $2.7 \%$ & 35 & $5.3 \%$ & $10.2 \%$ \\
\hline 1992 & 111 & $6.4 \%$ & $10.4 \%$ & 36 & $12.2 \%$ & $19.1 \%$ & 21 & $6.8 \%$ & $11.4 \%$ & 13 & $4.9 \%$ & $9.2 \%$ & 41 & $5.7 \%$ & $6.8 \%$ \\
\hline 1993 & 149 & $4.8 \%$ & $8.9 \%$ & 45 & $3.2 \%$ & $9.4 \%$ & 20 & $0.9 \%$ & $3.0 \%$ & 40 & $5.2 \%$ & $10.8 \%$ & 44 & $8.7 \%$ & $13.0 \%$ \\
\hline 1994 & 197 & $4.6 \%$ & $10.7 \%$ & 48 & $4.1 \%$ & $13.7 \%$ & 29 & $10.6 \%$ & $13.0 \%$ & 37 & $2.3 \%$ & $5.1 \%$ & 83 & $7.2 \%$ & $10.0 \%$ \\
\hline 1995 & 173 & $4.4 \%$ & $7.9 \%$ & 57 & $3.7 \%$ & $9.5 \%$ & 30 & $4.4 \%$ & $5.5 \%$ & 31 & $5.3 \%$ & $7.4 \%$ & 55 & $3.5 \%$ & $10.6 \%$ \\
\hline 1996 & 393 & $4.6 \%$ & $7.9 \%$ & 109 & $4.9 \%$ & $9.5 \%$ & 73 & $5.0 \%$ & $6.8 \%$ & 71 & $3.8 \%$ & $6.0 \%$ & 140 & $4.5 \%$ & $8.0 \%$ \\
\hline 1997 & 403 & $6.6 \%$ & $10.2 \%$ & 105 & $7.3 \%$ & $13.0 \%$ & 117 & $4.4 \%$ & $8.5 \%$ & 65 & $4.7 \%$ & $8.4 \%$ & 116 & $6.1 \%$ & $10.1 \%$ \\
\hline 1998 & 409 & $5.8 \%$ & $8.6 \%$ & 106 & $5.7 \%$ & $8.5 \%$ & 118 & $5.3 \%$ & $8.6 \%$ & 69 & $7.2 \%$ & $8.3 \%$ & 116 & $6.3 \%$ & $9.0 \%$ \\
\hline 1999 & 268 & $4.1 \%$ & $6.3 \%$ & 91 & $3.3 \%$ & $5.7 \%$ & 53 & $4.5 \%$ & $6.9 \%$ & 48 & $4.4 \%$ & $6.5 \%$ & 76 & $3.9 \%$ & $6.9 \%$ \\
\hline 2000 & 317 & $5.0 \%$ & $8.3 \%$ & 104 & $4.5 \%$ & $8.7 \%$ & 55 & $6.0 \%$ & $7.6 \%$ & 66 & $7.6 \%$ & $9.1 \%$ & 92 & $3.4 \%$ & $6.6 \%$ \\
\hline 2001 & 310 & $4.5 \%$ & $7.2 \%$ & 72 & $6.2 \%$ & $8.5 \%$ & 50 & $3.5 \%$ & $5.4 \%$ & 109 & $4.4 \%$ & $6.3 \%$ & 79 & $4.8 \%$ & $9.1 \%$ \\
\hline 2002 & 383 & $6.2 \%$ & $9.9 \%$ & 89 & $5.4 \%$ & $9.9 \%$ & 80 & $6.0 \%$ & $10.7 \%$ & 81 & $7.1 \%$ & $8.7 \%$ & 133 & $7.8 \%$ & $9.3 \%$ \\
\hline 2003 & 456 & $7.9 \%$ & $11.2 \%$ & 129 & $7.9 \%$ & $9.3 \%$ & 83 & $10.0 \%$ & $13.8 \%$ & 106 & $6.5 \%$ & $9.9 \%$ & 138 & $8.0 \%$ & $13.3 \%$ \\
\hline 2004 & 717 & $12.4 \%$ & $14.6 \%$ & 188 & $12.0 \%$ & $13.4 \%$ & 170 & $12.2 \%$ & $15.2 \%$ & 110 & $10.1 \%$ & $14.3 \%$ & 249 & $16.4 \%$ & $17.4 \%$ \\
\hline 2005 & 697 & $11.5 \%$ & $17.4 \%$ & 220 & $15.5 \%$ & $19.6 \%$ & 60 & $4.8 \%$ & $13.1 \%$ & 163 & $7.1 \%$ & $14.9 \%$ & 254 & $11.7 \%$ & $17.6 \%$ \\
\hline 2006 & 606 & $13.1 \%$ & $16.7 \%$ & 205 & $18.2 \%$ & $19.9 \%$ & 50 & $6.6 \%$ & $11.8 \%$ & 148 & $8.6 \%$ & $13.0 \%$ & 203 & $13.4 \%$ & $15.0 \%$ \\
\hline 2007 & 397 & $7.6 \%$ & $10.9 \%$ & 134 & $8.1 \%$ & $12.4 \%$ & 39 & $9.1 \%$ & $11.2 \%$ & 107 & $5.4 \%$ & $8.5 \%$ & 117 & $7.5 \%$ & $9.7 \%$ \\
\hline 2008 & 174 & $14.6 \%$ & $18.6 \%$ & 46 & $16.3 \%$ & $22.0 \%$ & 13 & $11.3 \%$ & $16.1 \%$ & 57 & $11.7 \%$ & $14.8 \%$ & 58 & $15.3 \%$ & $15.3 \%$ \\
\hline 2009 & 305 & $8.7 \%$ & $11.5 \%$ & 76 & $9.1 \%$ & $11.8 \%$ & 40 & $11.8 \%$ & $12.2 \%$ & 87 & $7.7 \%$ & $9.4 \%$ & 102 & $13.3 \%$ & $14.9 \%$ \\
\hline
\end{tabular}




\section{Table 6A:}

\section{Percentage Difference by Type of Appraisal}

This table presents statistics for the value-weighted percentage difference in sales price and appraised values two quarters prior to the sale date. Statistics are presented annually by date of appraisal on both an adjusted basis, where the adjustment rolls back sales price by the percentage capital gain from time of the appraisal until the time of the next quarter. External and Internal indicate that an external or internal appraisal was done two quarters prior to sale date; No Appraisal indicates that no new appraisal was done in that quarter. For each year, the table shows the median, mean, and standard error, as well as a t-statistic for the null hypothesis that the mean difference is zero, indicating that the appraisal is an unbiased estimate of the sales price. $*, * *$, and $* * *$ indicate that the mean is statistically different from zero at the $0.10,0.05$ and 0.01 levels, respectively.

\section{External}

Year Obs. Median Mean S.E. t-Stat.

$\begin{array}{rrrrr}\mathbf{A l l} & 1,583 & 1.0 \% & 1.9 \% & 0.4 \% \\ \mathbf{1 9 8 4} & 8 & -1.4 \% & -3.6 \% & 1.2 \% \\ \mathbf{1 9 8 5} & 3 & -1.7 \% & -12.4 \% & 8.8 \% \\ \mathbf{1 9 8 6} & 18 & -5.4 \% & -3.7 \% & 1.4 \% \\ \mathbf{1 9 8 7} & 11 & -11.0 \% & -6.4 \% & 3.8 \% \\ \mathbf{1 9 8 8} & 23 & 5.2 \% & 8.4 \% & 4.7 \% \\ \mathbf{1 9 8 9} & 35 & 1.5 \% & 0.7 \% & 1.4 \% \\ \mathbf{1 9 9 0} & 31 & -5.3 \% & -17.5 \% & 4.6 \% \\ \mathbf{1 9 9 1} & 7 & -1.5 \% & -4.8 \% & 3.5 \% \\ \mathbf{1 9 9 2} & 27 & -1.4 \% & 3.1 \% & 3.7 \% \\ \mathbf{1 9 9 3} & 36 & 0.7 \% & -1.0 \% & 2.1 \% \\ \mathbf{1 9 9 4} & 39 & 5.5 \% & 4.9 \% & 1.9 \% \\ \mathbf{1 9 9 5} & 17 & 3.3 \% & 1.4 \% & 2.1 \% \\ \mathbf{1 9 9 6} & 63 & 1.0 \% & 0.3 \% & 1.2 \% \\ \mathbf{1 9 9 7} & 46 & 0.3 \% & 2.2 \% & 1.2 \% \\ \mathbf{1 9 9 8} & 58 & 3.0 \% & 3.6 \% & 1.2 \% \\ \mathbf{1 9 9 9} & 46 & -1.6 \% & -1.1 \% & 1.2 \% \\ \mathbf{2 0 0 0} & 46 & -2.7 \% & -1.8 \% & 1.1 \% \\ \mathbf{2 0 0 1} & 68 & -0.5 \% & 1.4 \% & 1.1 \% \\ \mathbf{2 0 0 2} & 84 & 0.9 \% & -2.1 \% & 2.5 \% \\ \mathbf{2 0 0 3} & 86 & 6.2 \% & 6.2 \% & 1.6 \% \\ \mathbf{2 0 0 4} & 276 & 4.4 \% & 7.1 \% & 0.9 \% \\ \mathbf{2 0 0 5} & 106 & 7.1 \% & 7.9 \% & 1.2 \% \\ \mathbf{2 0 0 6} & 116 & 11.2 \% & 15.2 \% & 1.9 \% \\ \mathbf{2 0 0 7} & 89 & -0.1 \% & 2.0 \% & 1.3 \% \\ \mathbf{2 0 0 8} & 64 & -18.3 \% & -23.0 \% & 1.7 \% \\ \mathbf{2 0 0 9} & 180 & -0.6 \% & -2.9 \% & 1.1 \%\end{array}$

Internal

Obs. Median Mean S.E. t-Stat. $4.4 * * * \quad 1,759$ $-3.0 * * *$ $-1.4$ $-2.7 * * *$ $-1.7 *$

$1.8 *$

0.5 $-3.8 * * *$

$-1.4$

0.8

$-0.5$

$2.5 * *$

0.6

0.3

$1.9 *$

$3.0 * * *$

$-0.9$

$-1.6$

1.3

$-0.8$

$3.8 * * *$

$8.2 * * *$

$6.5 * * *$

$8.0 * * *$

1.5

$-13.6 * * *$

$-2.6 * * *$

\begin{abstract}
$1.6 \%$
$3.0 \% \quad 0.4 \%$
\end{abstract}

$4.2 \%$

$-0.5 \%$

$4.5 \% \quad 5.6 \% \quad 3.2 \%$

$-58.1 \% \quad-21.7 \% \quad 22.7 \%$

$-4.1 \% \quad-5.5 \% \quad 1.2 \%$

$-5.3 \% \quad-3.9 \% \quad 1.7 \%$

$5.7 \% \quad 4.0 \% \quad 2.2 \%$

$-39.2 \% \quad-28.5 \% \quad 10.8 \%$

$-0.4 \% \quad-25.4 \% \quad 9.9 \%$

$-0.1 \% \quad-2.1 \% \quad 2.6 \%$

$-1.9 \%-0.7 \% \quad 0.8 \%$

$3.9 \% \quad 8.9 \% \quad 1.8 \%$

$1.5 \% \quad 1.1 \% \quad 1.0 \%$

$1.4 \% \quad 1.2 \% \quad 0.9 \%$

$1.3 \% \quad 2.9 \% \quad 2.2 \%$

$-0.7 \% \quad 0.3 \% \quad 0.9 \%$

$2.3 \% \quad 6.8 \% \quad 1.3 \%$

$5.9 \% \quad 5.3 \% \quad 1.6 \%$

$9.8 \% \quad 7.4 \% \quad 1.5 \%$

$3.9 \% \quad 6.4 \% \quad 1.2 \%$

$4.8 \% \quad 7.1 \% \quad 0.9 \%$

$0.3 \% \quad 2.5 \% \quad 1.1 \%$

$-8.9 \% \quad-14.9 \% \quad 1.9 \%$

$3.0 \% \quad 3.0 \% \quad 1.3 \%$
No Appraisal

Obs. Median Mean S.E. t-Stat. $\begin{array}{llllll}7.8 * * * & 3,872 & 4.2 \% & 7.5 \% & 0.3 \% & 25.5 * * *\end{array}$ $\begin{array}{rrrrrr} & 36 & -4.2 \% & -3.7 \% & 1.2 \% & -3.0 \\ 1.7 * & 29 & 0.3 \% & 0.3 \% & 1.2 \% & 0.2\end{array}$ $\begin{array}{llllll}-0.2 & 95 & -0.9 \% & -1.3 \% & 1.1 \% & -1.2\end{array}$ $\begin{array}{llllll}-4.0 * * * & 78 & -0.8 \% & 3.6 \% & 1.7 \% & 2.1 * *\end{array}$ $\begin{array}{llllll}1.8 * & 95 & -2.8 \% & -5.4 \% & 1.3 \% & -4.2 * * *\end{array}$ $\begin{array}{lllll}-1.0 & 82 & -2.6 \% & -3.2 \% & 1.5 \%\end{array}$ $\begin{array}{lllll}-4.7 * * * & 89 & -1.7 \% & -4.7 \% & 1.3 \%\end{array}$ $\begin{array}{lllll}-2.3 * * * & 59 & -8.9 \% & -8.4 \% & 1.2 \%\end{array}$ $\begin{array}{lllll}1.8 * & 81 & 0.5 \% & -4.0 \% & 1.7 \%\end{array}$ $\begin{array}{lllll}-2.6 * * * & 103 & 0.7 \% & 0.1 \% & 1.2 \%\end{array}$ $\begin{array}{lllll}-2.6 * * * & 141 & 0.9 \% & 3.1 \% & 1.0 \%\end{array}$ $\begin{array}{lllll}-0.8 & 120 & -0.6 \% & -1.3 \% & 1.9 \%\end{array}$ $\begin{array}{lllll}-0.8 & 239 & 0.8 \% & 4.1 \% & 1.1 \%\end{array}$ $\begin{array}{lllll}4.9 * * * & 255 & 4.9 \% & 7.7 \% & 1.0 \%\end{array}$ $1.1 \quad 230$ $1.3 \quad 131$ 
Table 6B:

\section{Absolute Percentage Difference by Type of Appraisal}

This table presents statistics for the value-weighted percentage difference in sales price and appraised values two quarters prior to the sale date. Statistics are presented annually by date of appraisal on both an adjusted basis, where the adjustment rolls back sales price by the percentage capital gain from time of the appraisal until the time of the next quarter. External and Internal indicate that an external or internal appraisal was done two quarters prior to sale date; No Appraisal indicates that no new appraisal was done in that quarter. For each year, the table shows the median, mean, and standard error, as well as a t-statistic for the null hypothesis that the mean difference is zero, indicating that the appraisal is an unbiased estimate of the sales price. $*, * *$, and $* * *$ indicate that the mean is statistically different from zero at the $0.10,0.05$ and 0.01 levels, respectively.

External

\begin{tabular}{|c|c|c|c|}
\hline Year & Obs. & Median & Mean \\
\hline All & 1,583 & $7.9 \%$ & $11.6 \%$ \\
\hline 1984 & 8 & $3.7 \%$ & $4.9 \%$ \\
\hline 1985 & 3 & $7.7 \%$ & $12.5 \%$ \\
\hline 1986 & 18 & $5.8 \%$ & $7.3 \%$ \\
\hline 1987 & 11 & $6.1 \%$ & $10.7 \%$ \\
\hline 1988 & 23 & $9.1 \%$ & $15.0 \%$ \\
\hline 1989 & 35 & $8.6 \%$ & $7.8 \%$ \\
\hline 1990 & 31 & $4.0 \%$ & $9.2 \%$ \\
\hline 1991 & 7 & $2.8 \%$ & $6.7 \%$ \\
\hline 1992 & 27 & $4.9 \%$ & $10.0 \%$ \\
\hline 1993 & 36 & $5.5 \%$ & $7.8 \%$ \\
\hline 1994 & 39 & $5.0 \%$ & $8.6 \%$ \\
\hline 1995 & 17 & $4.7 \%$ & $6.8 \%$ \\
\hline 1996 & 63 & $6.1 \%$ & $9.7 \%$ \\
\hline 1997 & 46 & $4.7 \%$ & $7.2 \%$ \\
\hline 1998 & 58 & $7.4 \%$ & $11.2 \%$ \\
\hline 1999 & 46 & $6.9 \%$ & $7.2 \%$ \\
\hline 2000 & 46 & $5.6 \%$ & $8.0 \%$ \\
\hline 2001 & 68 & $5.4 \%$ & $7.7 \%$ \\
\hline 2002 & 84 & $7.8 \%$ & $11.3 \%$ \\
\hline 2003 & 86 & $6.6 \%$ & $10.1 \%$ \\
\hline 2004 & 276 & $12.6 \%$ & $14.6 \%$ \\
\hline 2005 & 106 & $8.8 \%$ & $12.0 \%$ \\
\hline 2006 & 116 & $8.6 \%$ & $14.5 \%$ \\
\hline 2007 & 89 & $5.2 \%$ & $9.0 \%$ \\
\hline 2008 & 64 & $16.0 \%$ & $19.3 \%$ \\
\hline 2009 & 180 & $10.9 \%$ & $13.3 \%$ \\
\hline
\end{tabular}

\section{Internal}

$\begin{array}{rrr}\text { Obs. } & \text { Median } & \text { Mean } \\ 1,759 & 7.0 \% & 11.3 \% \\ & & \\ 5 & 4.2 \% & 9.2 \% \\ 7 & 2.1 \% & 1.8 \% \\ 4 & 3.0 \% & 3.3 \% \\ 7 & 5.5 \% & 6.4 \% \\ 4 & 22.1 \% & 25.9 \% \\ 16 & 14.4 \% & 11.9 \% \\ 3 & 3.4 \% & 3.2 \% \\ 3 & 5.7 \% & 4.3 \% \\ 10 & 26.3 \% & 30.7 \% \\ 17 & 7.2 \% & 21.7 \% \\ 36 & 5.0 \% & 8.6 \% \\ 91 & 5.4 \% & 7.5 \% \\ 102 & 8.7 \% & 12.4 \% \\ 121 & 5.2 \% & 9.1 \% \\ 91 & 5.3 \% & 7.9 \% \\ 89 & 5.1 \% & 11.2 \% \\ 84 & 4.9 \% & 7.2 \% \\ 126 & 6.6 \% & 9.2 \% \\ 110 & 7.0 \% & 12.5 \% \\ 119 & 9.3 \% & 13.4 \% \\ 210 & 8.5 \% & 13.4 \% \\ 167 & 7.4 \% & 10.9 \% \\ 136 & 7.0 \% & 11.4 \% \\ 90 & 9.8 \% & 13.4 \% \\ 111 & 8.0 \% & 13.6 \% \\ & & \end{array}$

\begin{tabular}{|c|c|c|}
\hline \multicolumn{3}{|c|}{ No Appraisal } \\
\hline Obs. & Median & Mean \\
\hline 3,872 & $8.6 \%$ & $13.3 \%$ \\
\hline 36 & $9.1 \%$ & $9.6 \%$ \\
\hline 29 & $3.8 \%$ & $5.9 \%$ \\
\hline 95 & $6.5 \%$ & $8.8 \%$ \\
\hline 78 & $8.4 \%$ & $12.3 \%$ \\
\hline 95 & $10.6 \%$ & $13.0 \%$ \\
\hline 82 & $9.2 \%$ & $13.0 \%$ \\
\hline 89 & $13.5 \%$ & $12.0 \%$ \\
\hline 59 & $6.7 \%$ & $9.7 \%$ \\
\hline 81 & $8.4 \%$ & $12.6 \%$ \\
\hline 103 & $5.3 \%$ & $8.7 \%$ \\
\hline 141 & $6.2 \%$ & $11.2 \%$ \\
\hline 120 & $5.7 \%$ & $15.8 \%$ \\
\hline 239 & $6.5 \%$ & $11.9 \%$ \\
\hline 255 & $8.1 \%$ & $14.6 \%$ \\
\hline 230 & $7.4 \%$ & $11.3 \%$ \\
\hline 131 & $5.0 \%$ & $7.8 \%$ \\
\hline 182 & $5.9 \%$ & $9.0 \%$ \\
\hline 158 & $5.3 \%$ & $9.1 \%$ \\
\hline 173 & $7.9 \%$ & $10.7 \%$ \\
\hline 260 & $8.8 \%$ & $11.8 \%$ \\
\hline 322 & $15.6 \%$ & $18.2 \%$ \\
\hline 381 & $14.8 \%$ & $18.9 \%$ \\
\hline 323 & $14.2 \%$ & $19.3 \%$ \\
\hline 172 & $7.9 \%$ & $11.8 \%$ \\
\hline 20 & $8.8 \%$ & $14.1 \%$ \\
\hline 14 & $14.2 \%$ & $14.4 \%$ \\
\hline
\end{tabular}




\section{Table 7:}

Determinants of the Average Percentage Difference in Sales Price and Appraised Value This table presents the results from an ordinary-least-squares regression where the dependent variable is the quarterly average percentage difference in sales price and the two-quarter prior appraised value (value-weighted and adjusted for capital gains) and the explanatory variables are as indicated in the table. NPI Total Return, NPI Appreciation Return and NPI Income return refer to the quarterly returns of the NCREIF National Property Index. GDP Growth is the quarterly growth rate in U.S. GDP. Change in Unemployment Rate is the quarterly change in the U.S. national unemployment rate. 10-Year Treasury Rate is the yield on the 10-Year U.S. Treasury Bond. For each variable, the table presents the coefficient over its associated t-statistic. The sample period covers 106 quarters beginning with Q1 1984 and ending with Q4 2009. ****, and *** indicate that the mean is statistically different from zero at the $0.10,0.05$ and 0.01 levels, respectively.

\begin{tabular}{lcccc} 
& \multicolumn{4}{c}{ Panel A: NPI Total Return by Decade } \\
& $\mathbf{1 9 8 4 - 2 0 0 9}$ & $\mathbf{2 0 0 1 - 2 0 0 9}$ & $\mathbf{1 9 9 0 - 1 9 9 9}$ & $\mathbf{1 9 8 4 - 1 9 8 9}$ \\
NPI Total Return & $1.14 * * *$ & $1.37 * * *$ & $1.05 * * *$ & 1.05 \\
& 5.09 & 4.48 & 3.46 & 1.01 \\
Adj. R-Square & $0.192 * * *$ & $0.328 * * *$ & $0.220 * * *$ & 0.0001 \\
Obs. & 106 & 40 & 40 & 26
\end{tabular}

NPI Total Return

Panel B: NPI Return Components

NPI Appreciation Return

$1.14 * * *$

5.09

NPI Appreciation Return

$1.10 * * *$

$0.99 * * *$

NPI Income Return

4.73

4.38

NPI Income Return

Adj. R-Square

$0.192 * * *$

$0.169 * * *$

$5.95 * * *$

$7.30 * * *$

3.00

3.44

$0.229 * * *$

Obs.

106

106

106

106

\begin{tabular}{|c|c|c|c|c|c|}
\hline \multicolumn{6}{|c|}{ Panel C: NPI Total Return and Miscellaneous Macro-Economic Variables } \\
\hline \multirow[t]{2}{*}{ NPI Total Return } & $1.14 * * *$ & & & & $0.75 * * *$ \\
\hline & 5.09 & & & & 3.78 \\
\hline \multirow{2}{*}{ GDP Growth } & & $3.32 * * *$ & & & $2.01 * *$ \\
\hline & & 3.9 & & & 2.45 \\
\hline \multirow[t]{2}{*}{ Change in Unemployment } & & & $-0.52 * * *$ & & $-0.40 * * *$ \\
\hline & & & -5.23 & & -3.61 \\
\hline \multirow[t]{2}{*}{ 10-Year Treasury Rate } & & & & $-0.008 * * *$ & $-0.014 * * *$ \\
\hline & & & & -3.37 & -7.62 \\
\hline lj. R-Square & $0.192 * * *$ & $0.119 * * *$ & $0.201 * * *$ & $0.090 * * *$ & $0.523 * * *$ \\
\hline bs. & 106 & 106 & 106 & 106 & 106 \\
\hline
\end{tabular}




\section{Table 8:}

\section{Determinants of the Percentage Difference in Sales Price and Appraised Value}

This table presents the results from an ordinary-least-squares regression where the dependent variable is the percentage difference in sales price and the two-quarter prior appraised value (value-weighted and adjusted for capital gains) and the explanatory variables are as indicated in the table. NPI Appreciation Return and NPI Income Return refer to the quarterly returns of the NCREIF National Property Index. GDP Growth is the quarterly growth rate in U.S. GDP. Change in Unemployment Rate is the quarterly change in the U.S. national unemployment rate. 10-Year Treasury Rate is the yield on the 10-Year U.S. Treasury Bond. For each variable, the table presents the coefficient and its associated t-statistic. The sample period covers includes 7,213 properties sold from the NPI from Q1 1984 through Q2 2010. *,**, and *** indicate statistical significance at the 0.10, 0.05 and 0.01 levels, respectively. 


\begin{tabular}{|c|c|c|c|c|c|c|c|c|c|c|c|c|}
\hline Variable & Coef. & t-Stat. & Coef. & t-Stat. & Coef. & t-Stat. & Coef. & t-Stat. & Coef. & t-Stat. & Coef. & t-Stat. \\
\hline NPI Appreciation Return & 1.979 & $23.04 * * *$ & & & & & 1.392 & $14.08 * * *$ & & & 0.763 & $3.75 * * *$ \\
\hline NP Income Return & 0.724 & 1.03 & & & & & 1.674 & $1.96 * *$ & & & 10.877 & $2.30 * * *$ \\
\hline Change in Unemployment Rate & & & -0.886 & $-17.74 * * *$ & & & -0.450 & $-8.28 * * *$ & & & -0.285 & $-4.74 * * *$ \\
\hline GDP Growth & & & 0.625 & 1.36 & & & 0.991 & $2.05 * *$ & & & -0.253 & -0.44 \\
\hline 10-Year Treasury Rate & & & -0.016 & $-9.14 * * *$ & & & -0.018 & $-9.59 * * *$ & & & -0.010 & $-1.86 *$ \\
\hline External Appraisal & & & & & -0.052 & $-10.28 * * *$ & -0.036 & $-7.17 * * *$ & & & -0.037 & $-7.49 * * *$ \\
\hline Internal Appraisal & & & & & -0.045 & $-8.93 * * *$ & -0.037 & $-7.54 * * *$ & & & -0.032 & $-6.64 * * *$ \\
\hline Property is Levered & & & & & 0.046 & $11.22 * * *$ & 0.036 & $8.89 * * *$ & & & 0.025 & $6.29 * * *$ \\
\hline Office & & & & & 0.023 & $3.98 * * *$ & 0.019 & $3.41 * * *$ & & & 0.022 & $4.07 * * *$ \\
\hline Retail & & & & & 0.011 & 1.56 & 0.010 & 1.53 & & & 0.018 & $2.71 * * *$ \\
\hline Apartment & & & & & 0.029 & $4.35 * * *$ & 0.027 & $4.25 * * *$ & & & 0.028 & $4.46 * * *$ \\
\hline Y1990 & & & & & & & & & -0.094 & $-3.92 * * *$ & -0.049 & $-1.91 *$ \\
\hline Y1991 & & & & & & & & & -0.065 & $-1.76^{*}$ & -0.040 & -1.08 \\
\hline Y1992 & & & & & & & & & -0.009 & -0.27 & -0.005 & -0.14 \\
\hline Y1993 & & & & & & & & & -0.006 & -0.26 & -0.051 & -1.58 \\
\hline Y1994 & & & & & & & & & 0.011 & 0.49 & -0.045 & -1.50 \\
\hline Y1995 & & & & & & & & & 0.001 & 0.06 & -0.068 & $-1.95 *$ \\
\hline Y1996 & & & & & & & & & 0.037 & $2.30^{* *}$ & -0.027 & -0.91 \\
\hline Y1997 & & & & & & & & & 0.081 & $5.38^{* * *}$ & -0.004 & -0.13 \\
\hline Y1998 & & & & & & & & & 0.051 & $3.42 * * *$ & -0.035 & -1.03 \\
\hline Y1999 & & & & & & & & & 0.019 & 1.23 & -0.039 & -1.40 \\
\hline Y2000 & & & & & & & & & 0.037 & $2.45^{\star *}$ & -0.025 & -0.83 \\
\hline Y2001 & & & & & & & & & 0.004 & 0.26 & -0.041 & -1.25 \\
\hline Y2002 & & & & & & & & & 0.052 & $3.53^{* * *}$ & -0.012 & -0.37 \\
\hline Y2003 & & & & & & & & & 0.077 & $5.37^{\star * *}$ & 0.010 & 0.31 \\
\hline Y2004 & & & & & & & & & 0.113 & $8.39^{* * *}$ & 0.049 & 1.68 \\
\hline Y2005 & & & & & & & & & 0.132 & $9.75^{* * *}$ & 0.067 & $2.35 * *$ \\
\hline Y2006 & & & & & & & & & 0.145 & $10.86^{* * *}$ & 0.110 & $4.21 * * *$ \\
\hline Y2007 & & & & & & & & & 0.053 & $3.81^{* * *}$ & 0.044 & 1.50 \\
\hline Y2008 & & & & & & & & & -0.162 & $-10.36^{* \star \star}$ & -0.106 & $-3.02 * * *$ \\
\hline Y2009 & & & & & & & & & 0.010 & 0.69 & 0.062 & $1.96 * *$ \\
\hline Adjusted R-Square & 0.068 & & 0.066 & & 0.040 & & 0.119 & & 0.147 & & 0.173 & \\
\hline
\end{tabular}

